\title{
Recent Advancement in the Surface-Enhanced Raman Spectroscopy-Based Biosensors for Infectious Disease Diagnosis
}

\author{
Logan Hamm, Amira Gee and A. Swarnapali De Silva Indrasekara* \\ Department of Chemistry, University of North Carolina at Charlotte, 9201 University City Blvd, Charlotte, NC \\ 28203, USA; lhamm2@uncc.edu (L.H.); agee2@uncc.edu (A.G.) \\ * Correspondence: adesilva@uncc.edu; Tel.: +1-704-687-7848
}

Received: 4 March 2019; Accepted: 3 April 2019; Published: 6 April 2019

check for updates

\begin{abstract}
Diagnosis is the key component in disease elimination to improve global health. However, there is a tremendous need for diagnostic innovation for neglected tropical diseases that largely consist of mosquito-borne infections and bacterial infections. Early diagnosis of these infectious diseases is critical but challenging because the biomarkers are present at low concentrations, demanding bioanalytical techniques that can deliver high sensitivity with ensured specificity. Owing to the plasmonic nanomaterials-enabled high detection sensitivities, even up to single molecules, surface-enhanced Raman spectroscopy (SERS) has gained attention as an optical analytical tool for early disease biomarker detection. In this mini-review, we highlight the SERS-based assay development tailored to detect key types of biomarkers for mosquito-borne and bacterial infections. We discuss in detail the variations of SERS-based techniques that have developed to afford qualitative and quantitative disease biomarker detection in a more accurate, affordable, and field-transferable manner. Current and emerging challenges in the advancement of SERS-based technologies from the proof-of-concept phase to the point-of-care phase are also briefly discussed.
\end{abstract}

Keywords: optical biosensors; plasmonics; surface-enhanced Raman scattering; SERS; malaria; bacterial infections; diagnostics

\section{Introduction}

Accurate and timely diagnosis of infectious diseases is crucial for effective disease management and epidemic preparedness. Infectious diseases caused by parasites, viruses, bacteria, and fungi are responsible for 15 million deaths each year, while more than $95 \%$ of these deaths take place in low-income countries [1]. Among them, most of the mosquito-borne and bacterial infectious diseases are included in the list of neglected tropical diseases declared by World Health organization (WHO) that need to be controlled by 2030 [2,3], which emphasizes the current urge to develop rapid diagnostic tests for the early detection of infectious diseases. Current diagnostic modalities rely on highly sensitive polymerase chain reaction (PCR), which is technically challenging and expensive for widespread implementation in resource-limited settings, or light microscopy-based cytological examination, which has high specificity but poor sensitivity. Therefore, it is a timely need to develop new detection modalities that bring affordable, accurate, and highly sensitive characteristics to diagnostic tests.

Among new detection modalities, surface-enhanced Raman spectroscopy (SERS) has emerged as a powerful analytical technique for molecular analysis, which can be particularly advantageous for diagnostic purposes when the Raman spectroscopy is combined with inherent optical and chemical properties of plasmonic nanoparticles [4-13]. SERS is the main method of enhancing the inherently weak Raman intensity, such that Raman scattering can be widely utilized in analytical applications. 
In general, the Raman signal enhancement (commonly known as the SERS enhancement) is proposed to be a result of a combination of two main contributing phenomena, (i) electromagnetic enhancement (then main contributor) and (ii) chemical enhancement [14]. The electromagnetic enhancement is known to originate from the unique optical properties of plasmonic nanoparticles such as gold $(\mathrm{Au})$ and silver (Ag). Plasmonic nanoparticles are known to generate localized electromagnetic field when their size is smaller than the wavelength of the interacting light, which is known as localized surface plasmon resonance (LSPR) $[15,16]$. In SERS, this intense localized electromagnetic field of the plasmonic substrate is exploited to amplify the intrinsically weak Raman scattering cross-section of analytes when they are either on or in close proximity to a plasmonic substrate [14]. The LSPR and the magnitude of SERS enhancement can be modulated by changing the size, composition, shape, and the local environment of the NP [17-25]. In the context of SERS, plasmonic nanomaterial are referred to as SERS substrates and their effectiveness as a SERS substrate is evaluated by the SERS enhancement factor [26-29].

In SERS-based sensing applications, the optical transducer (SERS substrate) and the molecular functional interface are the two main elements that dictate the performance of sensors. The optical properties of a SERS substrate affect the analytical sensitivity while the functional interface of a SERS substrate determines the detection specificity. A great deal of work has been done in designing different types of plasmonic nanoscale substrates to improve the SERS enhancement factor, hence the analytical sensitivities. The first generation of SERS substrates were mainly composed of spherical gold or silver nanoparticles or substrates [30-33]. Anisotropic nanoparticles such as rod-, cubic-, triangle-, and star-shaped plasmonic nanoparticles and two-dimensional plasmonic substrates were then introduced [25,34-39]. Due to the higher electromagnetic field concentration imparted by the antenna effect of the sharp features of the second-generation SERS substrates, higher SERS enhancement factors could be achieved [38]. As the next generation of SERS substrates, nanoparticle assemblies and three-dimensional nanoscale plasmonic substrates were then emerged, and they contain plasmonic "hot spots", where the SERS enhancement factor is much greater [21,40-42]. In these nanoparticle assemblies, Raman active molecules are chemically or physically placed at the narrow gap between nanoparticles ("SERS hot spot") where they can experience the maximum SERS signal enhancement $[14,29,43,44]$. The evolution of SERS substrates has resulted in 10-12 orders of maximum Raman signal enhancement, which, under optimum condition, could facilitate even single-molecule detection.

The molecular functional interface of a biosensor, which is the interface between the optical transducer (plasmonic nanomaterials in SERS) and the biological environment, is the key element that needs to be carefully designed in order to attain high specificity, and hence, optimize the performance of a biosensor. There are two main factors that need to be considered when designing a functional interface of a nanobiosensor on SERS-based detection; (i) the stability of the SERS substrate in a biological sample matrix and (ii) the molecular recognition moieties (proteins, peptides, nucleic acids, aptamers) that specifically capture biomarkers such as cell membrane proteins, polysaccharides, lipids, or nucleic acids or a matrix that capture and retain the biomarkers or pathogens or infected cells. In addition, the physical distance between the transducer and the analyte should be kept at an optimum, which is $<5 \mathrm{~nm}$, to obtain the higher SERS signal enhancement $[14,45,46]$. Therefore, the distance dependence of the SERS signal intensity should also be taken into consideration when designing the molecular recognition moieties and/or spacers. Polymer-derivatives, polyethylene glycol, and surfactants are usually used as capping ligands or surface passivation ligands to ensure the colloidal stability of plasmonic SERS substrates and also to control the non-specific surface adsorption of biomolecules in biological samples [47,48]. Molecular reignition elements such as antibodies, enzymes, complementary nucleic acid, aptamers, and peptides are either use directly as it is or attached to a passivation ligand or a molecular spacer and then incorporated in the functional interface. Surface functionalization of SERS substrate with molecular reignition elements and surface passivation ligands takes the advantage of inherent high affinity of gold and silver nanomaterials towards molecules 
bearing highly electronegative or charged atoms such as nitrogen, sulfur, oxygen, etc., [49]. Therefore, molecular recognition elements are usually modified to contain a functional group such as thiol (SH), primary amine $\left(\mathrm{NH}_{2}\right)$, and carboxylic acid $(\mathrm{COOH})$ that can be attached to SERS substrates through dative covalent bonds to ensure strong and lasting surface attachment [50-53]. In some cases, molecular recognition elements such as proteins naturally possess primary amines or sulfur, which allows their direct attachment to nanoparticle surfaces. Ligands and molecular recognition elements modified with zwitterionic groups or the charged domains of the molecular reignition elements are also used to electrostatically attach them to plasmonic nanomaterial surfaces. Electrostatic interaction between the charged domains of the biomarkers, such as cell membrane proteins, are often used to directly capture, isolate, and retain the biomarker on plasmonic surfaces. In this case, the overall surface charge of the SERS substrate is modified using charged surface passivation ligands to tailor the functional interface depending on the biomarker of interest.

SERS as an analytical tool has been integrated into various disease diagnostic assays, including infectious diseases in two main formats; (1) label-free direct detection and (2) Raman label-enabled indirect detection. The direct detection format involves the adsorption of an analyte or the presence of an analyte in close proximity to a SERS substrate, which allows the analyte identification or quantification based on its unique SERS spectral fingerprints (intrinsic SERS signal) [54-59]. On the other hand, the indirect detection format uses a molecular recognition moiety on a SERS substrate, which capture analytes/biomarkers and bring them closer to the SERS substrate. The successful capture of analytes is then confirmed indirectly by monitoring the intense SERS signal of "reporter molecule" associated with the SERS substrate (extrinsic SERS signal) $[20,21,33,40]$. Reporter molecules are usually a dye or a molecule with high Raman scattering cross section that yield an intense SERS signal. Direct detection has the advantage of high specificity and capability to detect analytes without a known specific recognition element, but the spectral interference from the other components in the biological/sample matrix is a common issue. On the other hand, in indirect detection, spectral interference from the sample matrix is minimal as the analytes are isolated using molecular recognition elements, but it has the disadvantage of not being able to acquire the molecular information of the analyte/biomarker itself. Depending on the diagnostic need (binary identification, quantification, or multiplexing), and the sample matrix, the most appropriate SERS detection format could be selected.

In general, SERS-based sensing approaches have become more attractive and advantageous over conventional methods such as fluorescence due to ultra-sensitivity, even up to single-molecule detection, rich spectroscopic information provided on the molecular structure of interest that enable direct biomarker detection, and higher multiplexing capability [8,34,60-70]. Among these advantages, the multiplexed SERS detection, in particular, is very attractive in clinical settings as it allows for the detection of a panel of biomarkers ensuring higher confidence in the diagnosis and poses as a better alternative to the commonly used fluorescence-based multiplexed biosensing. This is because, (i) in comparison to fluorophores, Raman tags or Raman-active molecules are highly photostable, hence leading to stable SERS signal over a much longer analysis time. (ii) Raman/SERS peak widths are much narrower than fluorescence peaks, which leads to better spectral resolution, thereby facilitating higher-order multiplexing (in theory, >10) with spectrally unique Raman reporters, and (iii) different SERS tags used in a multiplexed assay can be detected under single-laser excitation source, but for each fluorophore used in a multiplexed biosensing assay, a separate laser excitation source is required. That means the less sophistication in instrumentation and experimental setup needed for SERS multiplexing is much more appealing when developing biosensors for point-of-care (POC) applications.

In this mini-review, we highlight the progress in the development in SERS-based diagnostic assays mainly for bacterial infections and mosquito-borne infections. In each section, the current SERS-based assays for common disease biomarkers (nucleic acid, proteins, and metabolites) followed by pre-sample preparation for SERS analysis and diagnostic device designs are discussed. Throughout the review, analytical figure of merits is provided as a guide to the reader to decide the quantitative and qualitative detection capabilities and limitations of each SERS-based diagnostic assays. Challenges 
and areas of improvements in designing SERS substrates and devices to transform these SERS-based technologies from the lab bench to the field are also briefly discussed. A summary of the highlighted work outlining the disease, biomarker, type of SERS detection (direct/indirect), transducer, and limit of detection (LOD) is also provided for the readers' benefit in the Table 1.

\section{Bacterial Infections}

SERS-based methods have enabled the detection of various types of bacterial biomarkers ranging from nucleic acids to proteins. The evolution of SERS-based detection methods improves the possibility of POC diagnostics by fabricating functional nanoparticles to achieve specific biomarker identification and higher SERS sensitivities. The functionality of nanoparticles can affect the efficiency and accuracy of target biomarker(s) detection. Device fabrication also plays a major role in the SERS-based detection of bacterial infections, particularly for field transferable applications. Recent advancements that have led to improved sensitivity and specificity in SERS-based bacterial infection detection are discussed in the following sections.

\subsection{Nucleic Acid Biomarkers}

Nucleic acids are a well-established group of biomarkers for detecting bacterial infections $[5,59$, 66,71-74]. Knowing the pathogenic DNA and RNA sequences facilitates the design of complementary strand(s) to specifically capture pathogenic RNA or single-stranded DNA, and hence, to identify them either directly or indirectly using SERS $[72,75,76]$. The nature of DNA and RNA, however, poses challenges in preparing sample to develop SERS-based diagnostic assays. The presence of smaller copy numbers of pathogenic nucleic acid biomarkers at the early stages of disease onset and their extraction and isolation from sample matrices make nucleic acid biomarker detection with no amplification very challenging. Therefore, as a common practice, synthetic nucleic acid sequences and also polymerase chain reaction (PCR)-amplified nucleic acid biomarkers from clinical samples are usually used in the proof-of-concept assays to optimize the assay parameters, and hence, the assay performance. Once the assay is optimized for analytical sensitivities and specificities, analysis in real biological/clinical samples with no nucleic acid amplification is carried out for field-transferable adaptation and optimization of the SERS-based diagnostic assays.

Most of the studies have used cultured bacterial suspensions to test SERS-based assays as a preliminary step for proof-of-concept testing $[7,59,66,72,73,77-86]$. The extraction of the DNA/RNA from the cultured bacterial cells of interest is crucial in order to remove background noise from other biomarkers, like cell membrane and metabolite biomarkers. The extracted nucleic acid is often amplified using PCR in order to reach the analytical sensitivities of the instrumentation as the concentrations of nucleic acid biomarkers are very low at early disease stages. For instance, Popp's group developed a combinatorial approach using PCR and SERS to detect epizootic pathogen DNA from cultured cells [72]. However, the sample preparation can be extensive when using PCR as it requires culturing of bacterial cells to extract DNA, followed by extensive purification and isolation steps. Clinical/biological samples have high background noise in SERS assays, which originates from the biological matrix in which the target DNA resides, therefore it requires more sample preparation. While sample preparation for nucleic acid detection has its inherent challenges, SERS-based high sensitivities at the picomolar to attomolar levels can still be achieved. For instance, in 2010, Bongsoo et al. used bacterial genomic DNA as the biomarker for four different pathogenic strains of bacteria and reported a limit of detection (LOD) of each pathogen ranging from $10 \mathrm{pM}-10 \mathrm{nM}$ using indirect SERS [66]. In their method, the target genomic DNA from four bacterial pathogens that causes various infections were first extracted and then amplified by PCR. The target DNA biomarkers for this study originated from reference bacteria and as well as clinically isolated samples such as cerebrospinal fluid, stool, pus, and sputum.

Among SERS-based nucleic acid detection methods, direct and indirect sandwich assays are the most common approach. It involves hybridization of a target nucleic acid sequence (target probe) with 
a capture sequence (capture probe) and reporter sequence linked to a Raman tag (reporter probe) and a plasmonic nanoparticle. For instance, Kim et al. presented an indirect SERS detection of PCR-amplified pathogenic DNA using a sandwich assay (Figure 1) [66]. They used two modified complementary DNA sequences, a $3^{\prime}$-thiol modified sequence attached to a gold nanowire (capture probe) and a $5^{\prime}$-Raman tag-modified sequence attached to gold nanoparticles through the $3^{\prime}$-thiol functional group (reporter probe), that hybridize specifically to two different sequence positions of the target DNA sequence. The complete hybridization of these three sequences is exhibited by the unique SERS signal of the Raman tag, indicating the presence of target DNA and resulting in a low LOD. Recently, Faulds's group also developed a new assay format for multiplexed SERS-based indirect detection and quantification of three meningitis pathogens using a sandwich assay [5]. They used two modified complementary DNA sequences to the target DNA sequence, a 3'-biotinylated modified sequence (capture probe) and a $5^{\prime}$-Raman tag-modified sequence (reporter probe). The newly formed duplex is retained on a streptavidin functionalized bead. Then, they used l-exonuclease to digest the double-stranded DNA. The DNA sequences are designed in such a way that the digestion product contains the Raman tag. The digestion products were then added to a solution containing silver nanoparticles for the SERS detection of the digestion product. The complete hybridization of these three sequences provides the unique SERS signal of the Raman tag, indicating the presence of the target DNA and resulting the LOD in the picomolar range. This approach provides higher specificity due to the hybridization between the target and two complementary sequences.

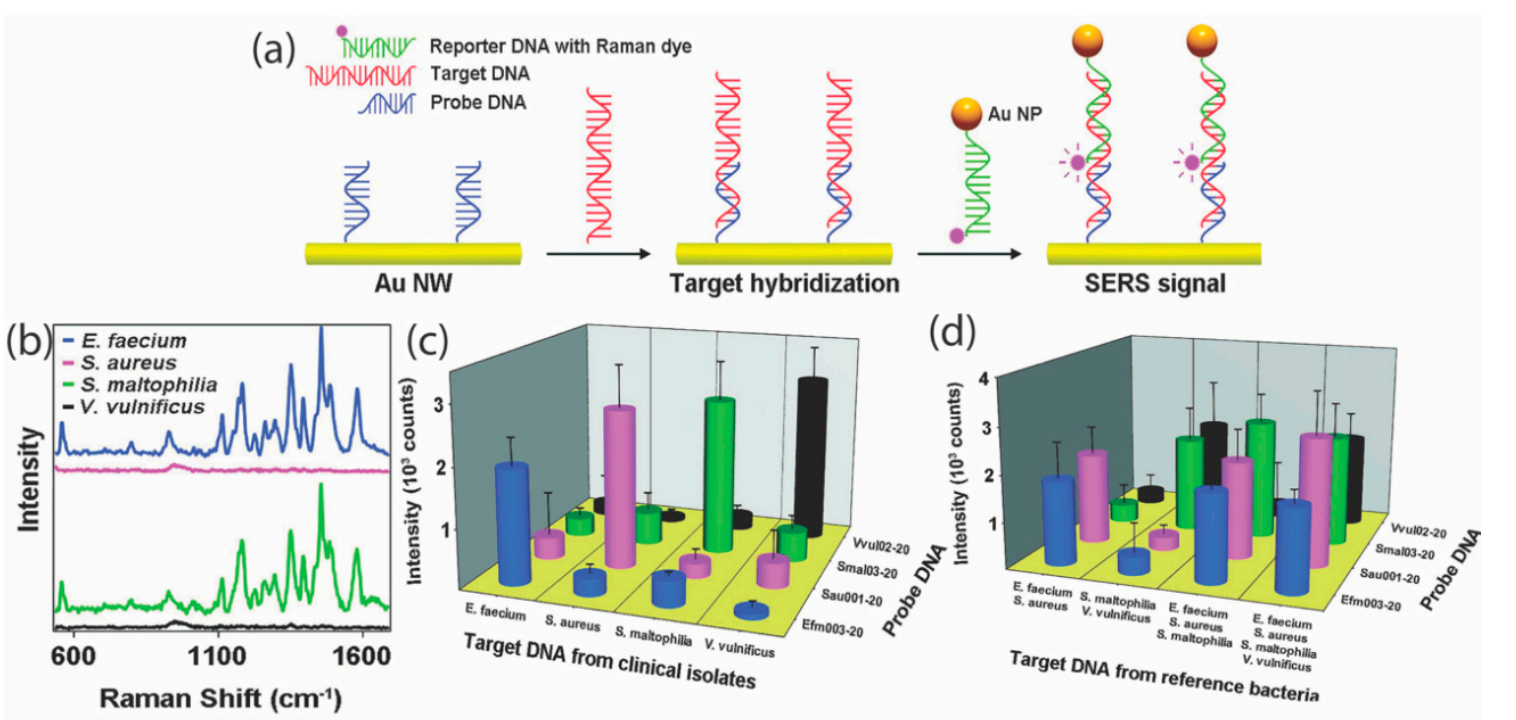

Figure 1. (a) An indirect surface-enhanced Raman spectroscopy (SERS)-based method for PCR-amplified pathogenic DNA detection. This method utilizes a sandwich hybridization event between a capture DNA sequence on gold nanowires and Raman reporter-labeled DNA sequence on with a target pathogenic DNA. (b) SERS spectra from each of the four nanowire systems in the presence of only the target DNAs of Enterococcus faecium and Stenotrophomonas maltophilia. SERS spectra of the Raman reporter (Cy5) detected only for E. faecium and S. maltophilia sensors. (c) SERS-based identification of amplified pathogenic DNA in clinical samples. (d) SERS-based multiplexed detection when all four target DNAs are present at $10^{-8} \mathrm{M}$ each. Reproduced with permission from Reference [66] American Chemical Society (2010).

Direct, label-free SERS detection of nucleic acids has also been used despite common indirect detection methods [73,74]. Kaminska et al. introduced a new class of label- free (direct SERS) SERS-based assay to detect Neisseria meningitidis, Streptococcus pneumoniae, and Haemophilus influenzae in cerebrospinal fluid (CSF) using their unique cell membrane biomarkers such as lipids and polysaccharides [74]. Their assay is based on the $\mathrm{Au}-\mathrm{Ag}$ coated polycarbonate membranes that allow simultaneous filtration of CSF and immobilization of CSF components to enhance their intrinsic 
SERS signature. This approach facilitates the direct detection of nitrogenous bases of target DNA and neopterin at the single-bacteria cell level. Direct detection of nucleic acids can be challenging because of the background noise from the biological matrix.

SERS-based diagnostic methods using clinical samples have also been conducted to determine the applicability towards POC applications [78-80,87-90]. Porter's group reported a novel sandwich SERS immunoassay for an antigenic biomarker for tuberculosis found in bodily fluids using a handheld Raman spectrometer [90]. They used serum samples to detect phospho-myo-inositol-capped lipoarabinomannan (PILAM), a stimulant of an antigenic biomarker found in tuberculosis infected patients. Their method requires sample pretreatment in order to eliminate any possible non-specific interaction between the PILAM and the other constituents found naturally in the serum sample. It is important to eliminate unnecessary biological interactions to ensure high detection specificity and, more importantly, to remove the biological matrix interferences to achieve high signal-to-noise ratio in SERS signal for high analytical sensitivity. The sample was acidified in order to denature proteins that could bind to PILAM. These denatured proteins and insoluble components were separated from the PILAM by centrifugation. The PILAM-enriched supernatant was extracted and neutralized to be used for a SERS assay. While the added sample pretreatment is not an extensive protocol, it shows the necessity of developing methods that require minimum or no sample preparation to transform these assays towards POC diagnosis of infectious bacterial diseases.

With impressive technological and technical growth in the microbiology and gene sequencing, a wide range of nucleic acids (DNA, RNA, non-coding RNA) biomarkers for disease diagnosis are being reported more frequently than before. Having access to such rich genetic information is highly beneficial to the scientists working in the POC SERS diagnostics as it will allow us to design SERS probes and assays that ensure high detection specificities and high-throughput detection protocols. This will immensely assist the performance of analysis in biological samples with no nucleic acid amplification carried out in the field-transferable adaptation and optimization of the SERS-based diagnostic assays.

\subsection{Cell Membrane Biomarkers}

Cellular membrane macromolecules, especially proteins, have proven to be a major pathogenic biomarker for SERS-based diagnostics [7,72,73,79-81,84-88,91]. Cell membrane proteins have been used as biomarkers to detect various bacterial infections such as Methicillin-resistant Staphylococcus aureus (MRSA) [73,86], urinary tract infection (UTI) [85], and strep throat [88]. For instance, Konkel's group used silver nanoparticles in solution for the direct, label-free SERS detection of proteins and nucleic acids in MRSA [73]. Cell membrane proteins in Escherichia coli and Proteus mirabilis cells that cause urinary tract infections have also been detected using intrinsic Raman signature (e.g., ring breathing/stretching, carbohydrate, and protein vibrations). In this study, the required sensitivity for intrinsic SERS-based detection was achieved using a SERS platform that was composed of silver nanoparticles decorated on a glass substrate [85], Assay development for cell membrane biomarker detection has been integrated into microfluidic devices [7,73,79] and in solution assays [80,81]. For instance, in 2013, Ray et al. reported the use of intrinsic SERS signature a cell membrane biomarker to detect MRSA with a $10 \mathrm{CFU} / \mathrm{mL}$ limit [86]. The SERS spectra produced from the MRSA cell wall consisted of peaks corresponding to ring breathing of tyrosine protein, saturated lipids, and other vibrational modes of cell membrane biomarkers. In order to achieve such high sensitivity in label-free detection, they used graphene oxide modified with an aptamer that selectively binds to Enterotoxin $\mathrm{B}$, which is a prominent MRSA protein, and gold nanopopcorn that provides good resolving power for SERS-based detection. It is reported that a higher analytical sensitivity was able to be achieved because they used the hybrid graphene oxide-based SERS substrates, which exhibited around 2 orders of magnitude higher SERS enhancement than only gold nanoparticle-based SERS substrates. They attributed the higher SERS enhancement effect originated from the hybrid graphene oxide-based SERS substrates to the contribution from both the electromagnetic and chemical enhancement effects 
simultaneously. This is an example that displays the improvements of the analytical sensitivities achieved by tailored designing of the SERS substrates.

In SERS-based diagnostic methods, protein biomarkers offer more advantages; (i) the ability to capture bacterial antigens using antibodies and (ii) the availability and accessibility of a larger quantity of proteins in comparison to nucleic acid biomarkers. Krause et al. used P30 and P65 proteins to detect and differentiate Mycoplasma pneumoniae strains FH, M129, and II-3 from clinical throat swabs and cultured bacteria [80]. They observed a variation in the concentration of proteins of interests between different strains of M. pneumoniae. Their results showed $>97 \%$ accuracy in identifying the strains from the throat swabs; thus, further displaying the clinical possibilities of SERS-based detection of protein biomarkers. This work shows the high sensitivity of SERS that enables protein biomarker detection that can even discriminate different bacterial pathogenic strains with increased specificity. Antibodies can act as good capture moieties due to specific binding affinity of proteins to antibodies, which ensures high analytical specificity for proteins biomarkers. Peripheral proteins, or surface proteins, are typically targeted as they can be easily accessible by nanoparticles to come in close proximity for SERS signal enhancement $[79,80]$. If a specific integral protein or a protein naturally found inside the cell is targeted, then the sample preparation for that method would require protein extraction from the bacterial cells. Added sample preparation can result in POC diagnosis being out of reach, however, protein has still proven to be a good biomarker for possible diagnosis in clinical settings [77,80,82,84-86,88,91]. Han et al. detected muramidase-released protein antibody against Streptococcus suis II in pig serum to demonstrate the potential clinical applicability of their indirect immuno-SERS assay [88]. While not all methods are clinically viable, some can be adapted for field-transferable applications. For example, Boyacı, İsmail et al. developed a method for indirect detection of E. coli in a water sample using a biotin-conjugated polyclonal antibody, which could be used by environmental scientists in the field [84].

Both direct and indirect SERS assays are commonly utilized for protein and cellular membrane biomarker detection. In comparison to nucleic acids, protein detection involves less sample preparation and nanoparticle fabrication. The close proximity of nanoparticles to the target bacteria provides an amplified Raman signal of the proteins, lipids, and carbohydrates directly, hence no extensive surface functionalization of nanoparticles is required [79,82,86,91]. Choi et al. used a gold nanoparticle-deposited paper for direct detection of cell membrane biomarkers in infectious keratoconjunctivitis (Figure 2) [91]. This method exhibited a SERS enhancement factor of $7.8 \times 10^{8}$, which shows that the current approach can result in good sensitivities without the functionalization of nanoparticles. Depending on what proteins are being detected, extraction may be necessary. Extracted protein samples can still be used in direct SERS detection assays. Indirect detection of proteins involves antibodies adhered to the nanoparticles through bioconjugation method. For instance, Boyac1, İsmail et al. used gold nanorods labeled with a Raman reporter and gold-coated magnetic nanoparticles both of which are functionalized with anti-E. coli antibodies for the detection of E. coli [84]. In this approach, immunoaffinity between the E. coli and anti-E. coli antibodies immobilized on gold-coated magnetic nanoparticles is first used to selectively separate and concentrate E. coli from the rest of the sample. Then, the resultant complex is allowed to form a sandwich with the anti-E. coli antibodies immobilized on gold nanorods for identification and quantification of E. coli using the SERS signal originated from the Raman reporter encoded in gold nanorods. Using this approach, they were able to achieve $8 \mathrm{CFU}$ $\mathrm{mL}^{-1} \mathrm{LOD}$ and $24 \mathrm{CFU} \mathrm{mL} \mathrm{m}^{-1}$ limit of quantification. 


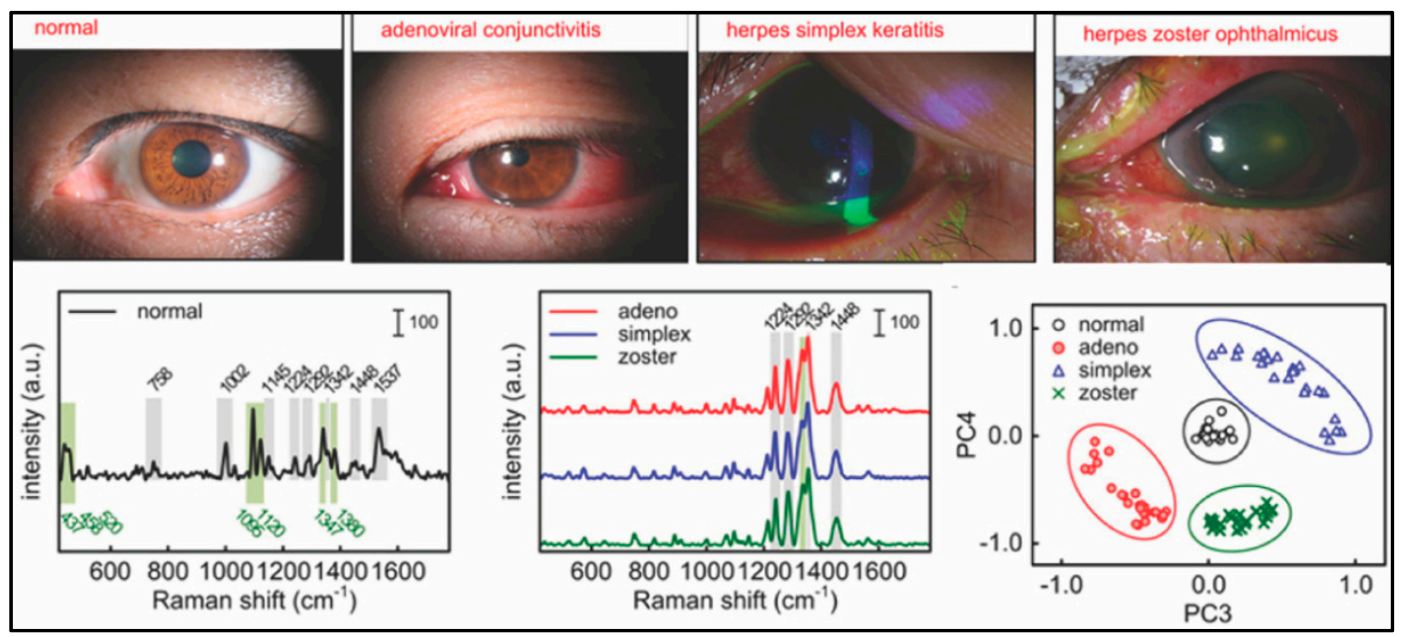

Figure 2. Direct, label-free cell membrane biomarker detection in bodily fluid using SERS. (Top) Photographs of a healthy and three types of keratoconjunctivitis, an infectious eye disease. Raman spectrum of (bottom left) a normal eye fluid and (bottom middle) fluid from the three types of eye infections. (Bottom right) PCA score plot classifying the normal and the three infected eyes based on the SERS spectra. Reproduced with permission from Reference [91] American Chemical Society (2016).

In general, immunoassays (traditional and SERS-based) that use protein biomarkers are still the most commonly used, widely studied, and even integrated into the commercialized diagnostics. However, in moving forward, we have two main important challenges to overcome; (i) the need for a known antibody for each protein biomarker and the cost associated with the production of antibodies for indirect SERS detection, and (ii) the complexity of the intrinsic SERS signature of proteins in direct SERS-based detection schemes. On a positive note, we believe that the current progress in finding alternatives to monoclonal antibodies, such as aptamers, and the machine learning for complex spectral analysis could contribute to overcome the abovementioned issues.

\subsection{Metabolites as Biomarkers}

In comparison to proteins and nucleic acids, cellular metabolites are not yet a common biomarker for SERS-based pathogen detection $[74,77,78,83,87,90]$. Metabolic processes can differ between bacteria that cause infections, therefore certain metabolites are targeted for increased specificity. Intrinsic SERS of metabolites is mostly used in direct SERS detection methods $[74,78,87]$. With the lack of work done on metabolites compared to proteins and nucleic acids, detection schemes are limited. Zughaier et al. targeted pyocyanin (PCN), a major secondary metabolic biomarker of Pseudomonas aeruginosa, which can cause pneumonia and urinary tract infections [78]. They and other groups reported above $90 \%$ sensitivity that can be achieved using similar bacterial metabolites $[74,78,87]$. Extensive background knowledge of the bacterium is necessary to understand the proper sample preparation and where the largest concentration of the metabolite resides. Sample fluids for metabolite detection of a bacterial pathogen can vary, ranging from clinical sputum, cerebrospinal fluid (CSF), to blood samples $[74,78,90]$. Sample preparation for metabolites can be challenging. Device substrates such as a "lab-on-a-chip" SERS platforms are common for metabolite detection. Ziegler et al. used an aggregated gold nanoparticle-covered silica substrate as a SERS substrate to detect urinary tract infection pathogens [87]. They used an in situ, two-step reduction method to synthesize the aggregated gold nanoparticles on the silica substrate (Figure 3). With this device, they directly detected the vibrational modes of nucleic acid metabolic degradation metabolites such as adenine, hypoxanthine, xanthine, guanine, uric acid, and adenosine monophosphate. Direct detection suits for this method because of the varying concentrations of abovementioned metabolites in the extracellular region of different bacterial strains creating unique, intrinsic SERS spectra. Their work displayed $>95 \%$ sensitivity 
and $>99 \%$ specificity for direct SERS detection of target metabolites. With current methods achieving high sensitivities, metabolite detection does have a promising future in POC applications $[74,78,87,90]$. While it is still in its infancy to exploit the metabolites of the pathogen in the SERS biosensing assay, in our opinion, the metabolites could be one of the best biomarker options as they facilitate simple label-free SERS detection. Simplicity in the assay development and the detection scheme could be highly favorable for POC applications. We hope that more metabolite-based SERS diagnostic assays will be seen in the future as biologists better understand the molecular level processes of the pathogens.
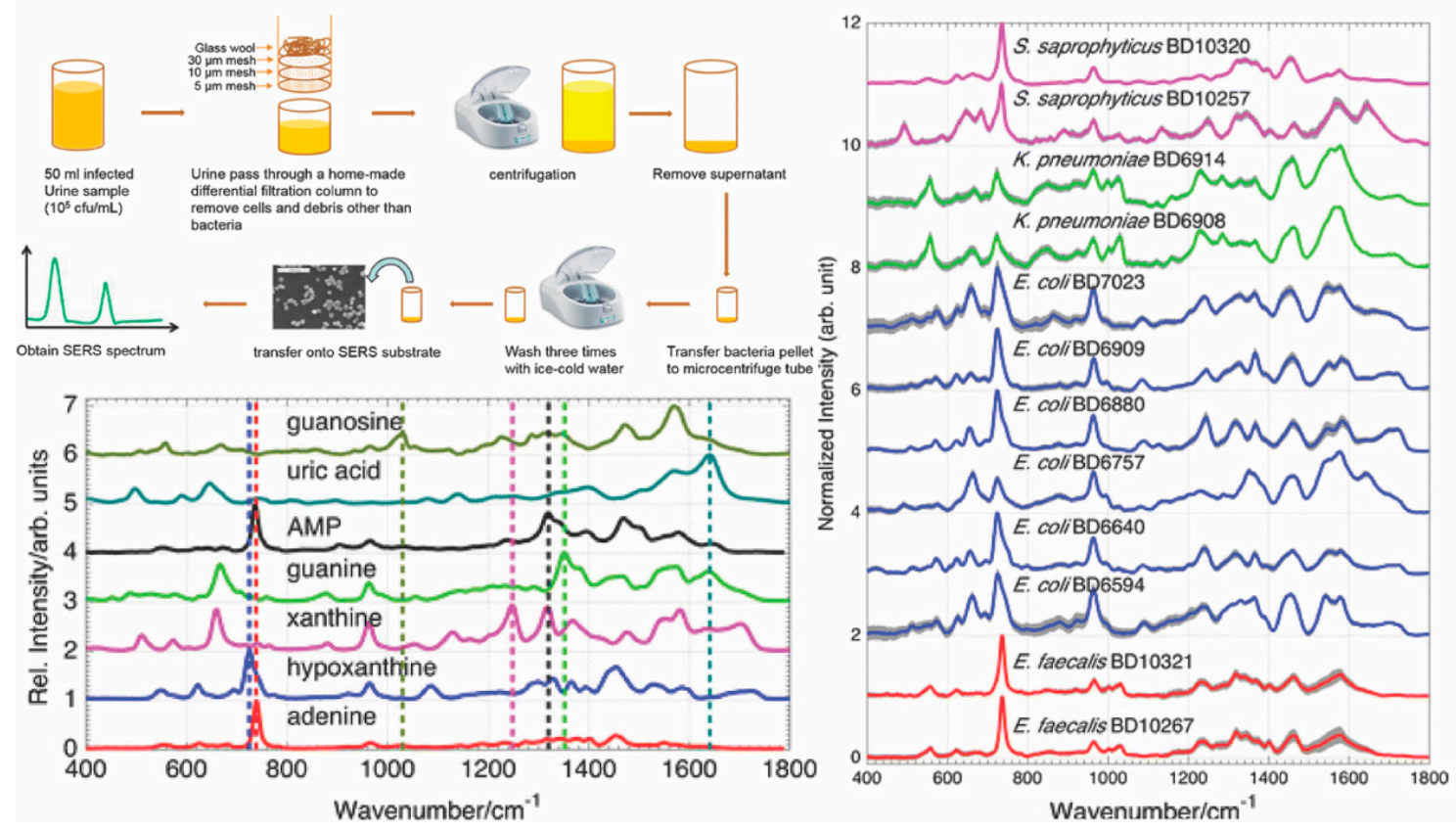

Figure 3. (Top Left) Sample preparation steps for urine samples spiked with bacterial strains of urinary tract infection (UTI) clinical isolates for SERS-based direct detection of nucleic acid metabolites. (Right) SERS spectra of 12 different UTI bacterial strains exhibiting unique biomarker signatures that were produced from sample on an aggregated gold nanoparticle-covered silica substrate. (Bottom Left) Intrinsic SERS spectra of seven key metabolite biomarkers used in the differentiation of the 12 UTI bacterial strains. Reproduced with permission from Reference [87] Springer (2017).

\section{Mosquito-Borne Infections}

Mosquito-borne diseases such as Malaria, dengue, West Nile Virus, River Valley Fever, and Zika are caused by either a virus or parasite, and they have gained the most attention in the global health-focused communities for the last few decades. These diseases are usually diagnosed by a blood test to identify the presence of parasites or virus. In order to improve the timely diagnosis of mosquito-borne infectious disease, specific biomarkers must be analyzed through more robust diagnostics. Herein, we discuss advances in the SERS-based approaches for the sensitive detection of mosquito-borne infectious disease biomarkers.

\subsection{Nucleic Acid Biomarker Detection}

Nucleic acids, both DNAs and RNAs (coding and non-coding), are valuable biomarkers for infectious disease detection. In 2011, Zhang et al. designed a proof-of-concept SERS assay to detect DNA oligonucleotides obtained from the West Nile virus (WNV) genome. They used the classical sandwich assay where hybridization between the complementary oligonucleotide probes covalently linked to paramagnetic nanoparticle (capture probe) and Raman-reporter conjugated-gold nanoparticles (reporter probe) and the target DNA sequence to design an indirect SERS assay for WNV detection [92]. They later simplified this method to do multiplexed detection of viral DNA of WNV and 
Rift Valley virus (RVFV) and also intensify the SERS response by magnetic enrichment [93]. They used a capture probe attached to a gold-coated paramagnetic nanoparticle that have both magnetic and SERS properties, and a reporter probe with a Raman tag as the key components. Each of these probes has specific complementary oligonucleotide sequences to the opposing ends of the target WNV DNA sequence. In the presence of the target DNA, a hybridized complex between capture-target-reporter probe is formed. It is then magnetically enriched using Au-coated paramagnetic nanoparticle and the SERS signal is recorded. Herein, the capture of target DNA is indirectly detected by monitoring the SERS spectrum of the Raman tag associated with the reporter probe. The LOD was determined to be in the low nanomolar range (20-100 $\mathrm{nM})$ requiring only $1 \mathrm{~h}$ for the assay.

Lab-on-a-chip SERS substrates are another common approach for DNA biomarker detection. The Vo-Dinh group at Duke University developed a bioassay-on-chip using plasmonic bimetallic nanowave to detect dengue viral DNA [94]. They used gold and silver nanowaves to develop a highly sensitive SERS substrate, which was subsequently functionalized with reporter probes carrying a Raman tag for dengue viral DNA. They designed a new type of reporter probe with a placeholder, which is covalently linked to the plasmonic nanowaves. In the absence of the target sequence, the reporter probe and the placeholder maintain a partially duplex complex. It keeps the Raman tag at the end of the reporter probe away from the SERS substrate at a distance where the SERS effect is negligible and therefore no significant SERS signal is detected-SERS "off" state. In the presence of target viral DNA, placeholder hybridizes with the target DNA, leaving the reporter probe to form a hair loop. This hair loop structure brings the Raman tag back into very close proximity to the SERS substrate (SERS “ON") hence producing a measurable SERS signal. The LOD of this approach was determined to be 6 attomoles. The same group later developed another simpler detection strategy based on sandwich DNA hybridization to detect malaria DNA biomarkers [95]. The target DNA was identified using single nucleotide polymorphism discrimination via ultrabright SERS nanoparticles known as nanorattles and then enriched using magnetic beads. The ultrabright nanorattles are functionalized with SERS reporter DNA probes and the magnetic beads are coated with the capture DNA probes. Once the target DNA is introduced, complexation of magnetic beads and nanorattles takes place due to the sandwich DNA hybridization between target-capture and reporter DNA probes. This allowed them to concentrate hybridized complex in a localized position using a magnet for SERS measurements and achieve LOD at 3 picomolar.

The most recent work by the Vo-Dinh group reported a highly sensitive SERS-based diagnostic assay to detect Malaria ribosomal RNA (rRNA) in blood lysates without target amplification [96]. They introduced a lab-in-a-stick portable device concept that process blood samples for SERS-based detection of 18s rRNA (unamplified) from the Malaria parasite (Figure 4). Their detection strategy involves ultrabright SERS-encoded nanorattles. The nanorattle-based sandwich assay used magnetic beads functionalized with capture probes and nanorattles with reporter probes. In the presence of target, hybridized nanoparticle complex forms a pellet, which is localized inside the capillary tube using a magnet while leaving any unreacted analytes or other biological components behind. Passing the pellet through different washing compartments inside the capillary tube with the assistance of a magnet, non-specific binding can be largely eliminated/removed, thereby ensuring high specificity in the recorded SERS measurements. The most appealing feature of this approach is that it involves no RNA extraction nor PCR amplification yet achieves an LOD at $200 \mathrm{fM}$ in Malaria-infected blood samples, which exhibits more field-transferable characteristics for a SERS diagnostic assay. 

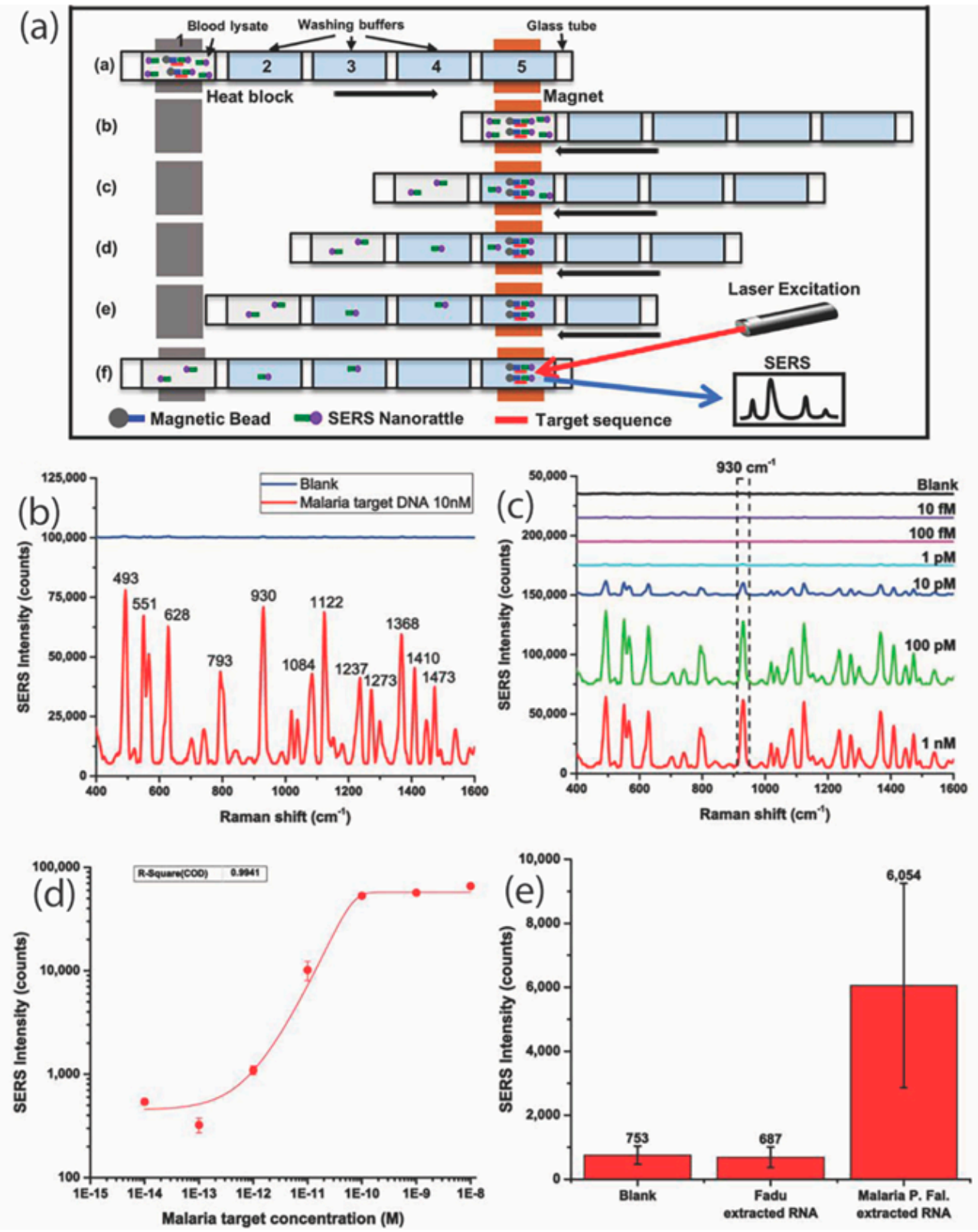

Figure 4. (a) Direct detection of plasmodium falciparum, malaria parasite, using an unamplified DNA and RNA biomarker. RNA biomarker sequence hybridized to the capture probe sequence on a magnetic bead and the reporter probe sequence on an ultra-bright SERS nanorattle with in a lab-in-a-stick device detection scheme. (b) SERS spectra displaying malaria synthetic DNA versus blank and (c) Malaria synthetic DNA with a concentration range of $10 \mathrm{fM}$ to $1 \mathrm{nM}$. (d) Quantification of target DNA using the SERS intensity at the reporter signature peak at $930 \mathrm{~cm}^{-1}$, (e). Malaria P. falciparum $18 \mathrm{~s}$ rRNA detection in blood lysate. Reproduced with permission from Reference [96] Scientific Reports (2018).

\subsection{Proteins}

Antibodies are used in immunoassays to detect protein biomarkers associated with infectious diseases. Brolo et al. used SERS nanoprobes in an immunoassay to detect Zika virus [97]. They used gold shell-isolated nanoparticles as the SERS substrate, where a Raman reporter (Nile Blue) is embedded in a silica shell to prevent leaching and the silica surface is functionalized with monoclonal anti-Zika NS1 antigens. This method was able to ensure high specificity that they observed no cross-reactivity with DENV NS1 antigens and to provide $10 \mathrm{ng} / \mathrm{mL}$ LOD for ZIKV NS1. In 2010, 
Johnson et al. focused on designing a SERS immunoassay to detect the WNV. They used WNV antigen-coated gold nanostars and matchite green Raman reporter-conjugated proteins. When the antigen functionalized gold nanostars captures the target WNV proteins, it can be detected using the Raman spectral signature of matchite green. The LOD of this SERS immunoassay was determined to be $2 \mathrm{ng} / \mathrm{mL}$ while resulting sensitivity of $50 \mathrm{pg} / \mathrm{mL}$ [98]. Later, they designed another type of SERS immunoassay to detect the surface envelope and capsid antigens of WNV and RVF. Raman reporter coated-gold nanoparticles and paramagnetic nanoparticles were conjugated with disease specific polyclonal antibodies, which resulted LOD near $5 \mathrm{fg} / \mathrm{mL}$ [99]. Then, in 2018, they reported multiplexed immunoSERS for the detection of viral pathogenic antigens associated with WNV, RVF, and Yersinia pestis [100]. Both magnetic nanoparticles and SERS reporter-embedded silica-coated gold nanoparticles were functionalized with the polyclonal antibodies in order to capture the disease specific antigens. An external magnetic field was used to aggregate the antigen-, magnetic nanoparticle-, and silica-coated gold nanoparticle complex. The unique SERS spectrum of the Raman tags embedded in the silica-coated gold nanoparticles was then used to indirectly detect each captured antigen, which has enabled the multiplexed SERS-based protein biomarker detection with the LOD at $10 \mathrm{pg} / \mathrm{mL}$.

Protein-induced plasmonic nanoparticle aggregation has also been used to detect protein biomarkers using their intrinsic SERS signatures (direct SERS). Kah et al. used gold nanostars (GNS) to design an approach for label-fee direct SERS detection of Enterovirus 71 (EV71) [101]. This approach is very attractive for POC diagnosis given the fact that it is based on the intrinsic SERS of proteins (Figure 5). In this study, GNS were conjugated to a recombinant scavenger receptor class B, member 2 (SCARB2) protein, which has an established affinity for EV71. When the GNS-SCARB2 is introduced to the infected sample, they conjugate to EV71hence facilitating the direct detection of EV71 while preventing GNS aggregation. This method has yield LOD comparable to other approaches at $10^{6}$ to $10^{8} \mathrm{pfu} / \mathrm{mL}$. In addition, the high sensitivity $\left(10^{7} \mathrm{pfu} / \mathrm{mL}\right)$, low amount of sample preparation, and only 15-minute analysis time are favorable characteristics, which make this assay more appealing for POC applications. Recently, Hamad-Schifferli's group developed a multiplexed SERS-based dipstick immunoassay to distinguish between Zika and dengue [102]. In this study, they used SERS tags-encoded GNS conjugated to Zika and dengue specific antibodies to detect nonstructural protein 1 (NS 1) specific to Zika and dengue as the biomarkers (Figure 6). This diagnostic assay combined the simplicity of lateral flow assay (LFA) with the high sensitivity of SERS where 15-fold and 7-fold LOD for Zika and dengue biomarkers, respectively. Serum and saliva have also been used as sources of diagnostic protein biomarkers for mosquito-borne diseases. Ray et al. used anti-flavivirus 4G2 antibody conjugated gold nanoparticle with Raman probes to detect dengue and WNV in serum samples. The LOD was determined to be $10 \mathrm{PFU} / \mathrm{mL}$ for both dengue and WNV due to the plasmon coupling in nanoassembly [103]. 
(a)

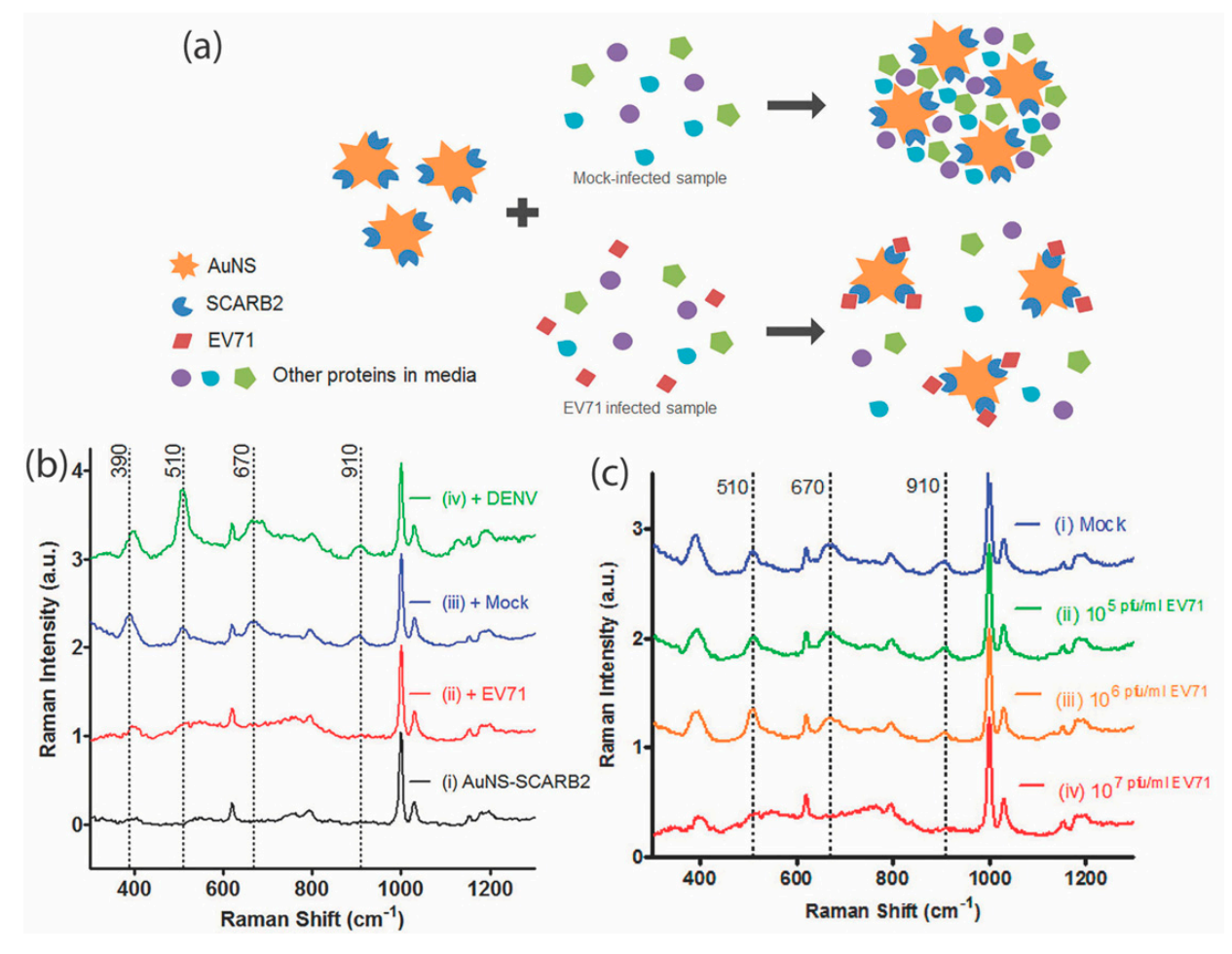

Figure 5. Direct, label-free SERS-based detection of enterovirus 71 using gold nanostars conjugated to recombinant scavenger receptor class B, member 2 (SCARB2) protein. (a) Schematic representation of the enterovirus 71 detection by SCARB2 protein- functionalized gold nanoparticles. (b) SERS spectral differences of AuNS-SCARB2 in the presence of EV71 in comparison to other control proteins, which indicates analytical specificity of this approach and (c) concertation dependence of the SERS intensity of the AuNS-SCARB2- EV71 conjugate. Reproduced with permission from Reference [101] American Chemical Society (2011).
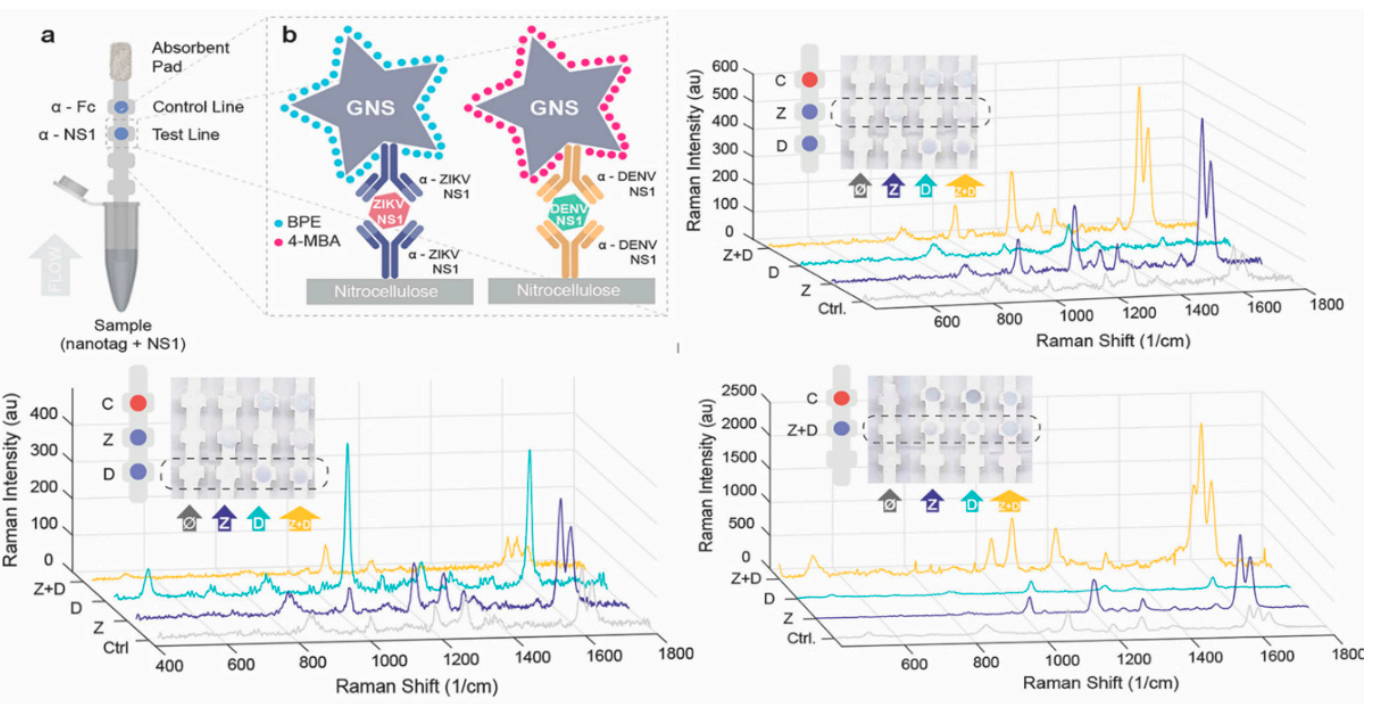

Figure 6. Multiplexed SERS-based indirect detection of Zika and dengue using dipstick sandwich immunoassay. (top left) Schematic diagram of dipstick immunoassay where sandwiches are formed by each antibody pair, NS1, and gold nanostars-Ab conjugate for both ZIKV and DENV NS1. SERS spectra of (top left) Zika and (bottom left) dengue test line separately and (bottom right) both Zika and dengue in the same test line. Samples: The control (C) (gray), ZIKV NS1 (blue), DENV NS1 (cyan), and a mixture of ZIKV and DENV NS1 (yellow). Reproduced with permission from Reference [102] American Chemical Society (2011). 


\subsection{Metabolites as Biomarkers}

Changes in the red blood cells (RBC) have been traditionally used to detect mosquito-borne infection, and it has also been found that some of the molecular changes in RBC can also be detected using SERS to potentially achieve high diagnostic sensitivities. Zhao's group at the University of Georgia used the SERS spectral features apparent in RBC infected with Plasmodium falciparum (iRBC) to differentiate varying stages of the parasite in the blood as iRBC at different post-invasion times exhibit different cell membrane modifications [104]. In this study, they analyzed and compared the intrinsic spectral signatures of healthy RBC and iRBC on silver nanorod array substrates. For instance, a unique SERS peak at $\Delta \mathrm{v}=1599 \mathrm{~cm}^{-1}$ for ring stage iRBCs, and a SERS speak characteristic to trophozoite, and schizoid stages were at $\Delta \mathrm{v}=723 \mathrm{~cm}^{-1}$ identified while none of them were present in healthy RBC (Figure 7). This intrinsic SERS-based assay reported $1.5 \times 10^{7} / \mathrm{mL}$ LOD for both RBCs and iRBCs. In addition, there are several other reports that uses either Raman or resonance Raman to identify the erythrocyte membrane alterations at iRBC at different post-invasion times [105-108].

Hemozoin, a metabolite found in malaria-infected blood has also been used as a biomarker for early malaria diagnosis [109-112]. In 2012, Yuen et al. used SERS-active magnetic nanoparticles composed of iron oxide core and silver shell to detect hemozoin in iRBC based on its intrinsic SERS signature [113]. Hemozoin, which is paramagnetic in nature, was enriched using an external magnetic field on the iron oxide core and then the amplified SERS signal on silver shell was measured. They observed that the SERS signal without the use of the magnetic field is about two orders of magnitude lower than signals reported without the magnetic enrichment (Figure 7). The LOD for $\beta$-hematin was determined to be $5 \mathrm{nM}$, which is approximately equivalent to 30 parasites $/ \mu \mathrm{L}$ present at the early stages of malaria infection [113]. The same group later developed a method for SERS-based hemozoin detection in iRBC using only plasmonic nanoparticle, but with no need for an external magnetic field [109]. This improvement was done in order to eliminate any additional variation in SERS readings that could have originated from the magnetic enrichment and hence improve the SERS-based quantification capability. They used two approaches; (i) synthesized silver nanoparticles in the blood or (ii) pre-synthesized silver nanoparticles added to a blood sample. The first approach has exhibited lower variation in the SERS measurement, which could be more suitable for quantification of the parasitemia level. On the other hand, the second method has resulted in a higher sensitivity, with the LOD as low as $0.00005 \%$ parasitemia level in the ring stage, which is approximately 2.5 parasites $/ \mu \mathrm{L}$ of blood. The reported LOD is comparable to the most sensitive detection techniques currently available, thus this approach could be more effective in early malaria diagnosis. Wood et al. also developed a novel SERS platform, which is composed of gold-coated butterfly wings for SERS-based direct detection of malarial hemozoin in lysed blood samples [114]. Using this new SERS platform, they identified key characteristic spectral features of the hemozoin in the iRBC lysate (e.g., strong pyrrole in-phase breathing vibration peak at $1375 \mathrm{~cm}^{-1}$ ) that indicate the presence of early-ring stage parasitemia levels and provided the LOD between $0.0005 \%$ and $0.005 \%$. 


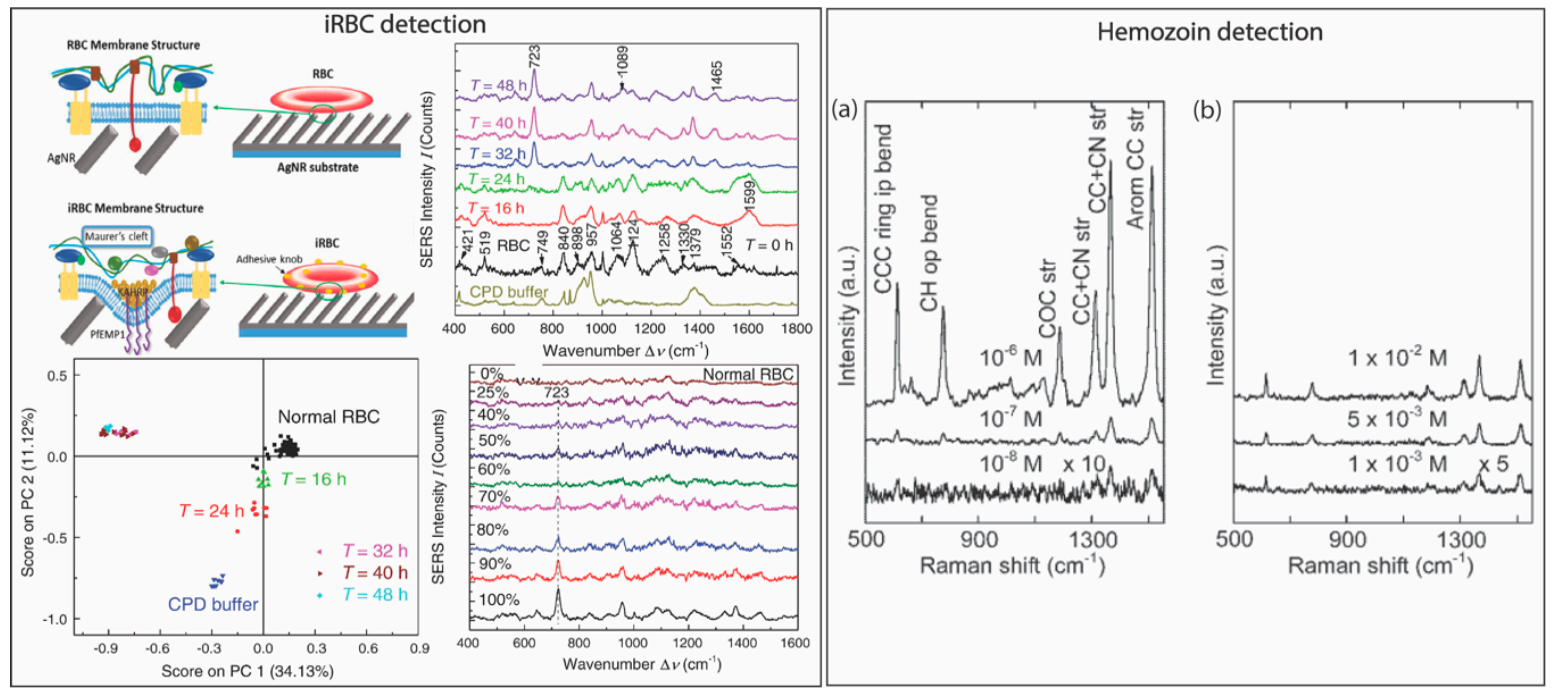

Figure 7. SERS-based malaria metabolite detection. Intrinsic SERS signature of infected red blood cells (iRBC) using silver nanoparticle substrates. (top right) iRBCs with different infection time (up to $24 \mathrm{~h}$ : ring stage, after $32 \mathrm{~h}$ : late-stage trophozoite and schizont stage iRBCs). (bottom left) Principle component analysis (PCA) score plot for RBCs and different stages of iRBCs based on their SERS spectra. (bottom right) The SERS spectra of the mixtures of RBCs and schizont stage iRBCs at varying percentages. Reproduced with permission from Reference [104] Science Direct (2016). Detection of $\beta$-hematin crystals in blood as a malaria metabolite biomarker using magnetic nanoparticles with iron oxide and a silver shell. (a) Intrinsic SERS spectra showing the unique peak profile of $\beta$-hematin at varying concentrations and $(\mathbf{b})$ changes in concentration of the target biomarker. Reproduced with permission from Reference [113] SPIE (2012).

\section{SERS-Based Diagnostic Devices and Assay Platforms}

Integration of biosensors into technological platforms/prototypes for field testing is critical in its transformation from the bench to the clinics or field. In particular, The World Health Organization (WHO) has identified the characteristics of a POC diagnostic that are appropriate for even the lowest-resource limited settings. They coined the acronym "ASSURED" to highlight affordable, sensitive, specific, user-friendly, rapid and robust, equipment free, and deliverable to users as the main characteristics of a diagnostic biosensor. While accuracy, accessibility, and affordability are the three main important factors, some characteristics have to be traded off to prioritize others based on the application. 
Table 1. Summary of SERS-based biomarker detection methods for bacteria and mosquito-borne infectious diseases.

\begin{tabular}{|c|c|c|c|c|c|}
\hline Disease & Target & Detection Scheme & Transducer & LOD & Ref. \\
\hline \multicolumn{6}{|c|}{ Bacterial Infections } \\
\hline $\begin{array}{l}\text { Various bacterial infections: E. faecium, S. } \\
\text { aureus, S. Maltophilia and V. vulnificus }\end{array}$ & $\begin{array}{l}\text { DNA extracted from clinical samples of } \\
\text { cerebrospinal fluid, stool, and sputum }\end{array}$ & Indirect SERS & Gold nanowires \& nanoparticles & $10 \mathrm{pM}$ & [66] \\
\hline $\begin{array}{l}\text { Bacterial meningitis pathogens: } N \text {. } \\
\text { meningitidis, S. pneumoniae and H. influenzae }\end{array}$ & Synthetic DNA & Indirect SERS & Silver nanoparticles & pM range & [5] \\
\hline contagious bovine pleuropneumonia (CBPP) & $\begin{array}{c}\text { MmmSC_1046 (lipoprotein lppQ), MmmSC_0136 } \\
\text { (hypothetical transmembrane protein), and } \\
\text { Botau_12S (mitochondrial 12S rRNA) }\end{array}$ & Indirect SERS & $\begin{array}{l}\text { streptavidin-modified magnetic } \\
\text { nanoparticles \& silver nanoparticles }\end{array}$ & Not reported & [72] \\
\hline $\begin{array}{l}\text { Bacterial meningitis pathogens: } N \text {. } \\
\text { meningitidis, S. pneumoniae and H. influenzae }\end{array}$ & $\begin{array}{l}\text { Unique Nitrogen base composition of target } \\
\text { DNA \& Neopterin (metabolites) }\end{array}$ & Direct SERS & $\begin{array}{l}\text { polycarbonate membranes coated with } \\
\text { gold \& silver }\end{array}$ & Neopterin: nM range & [74] \\
\hline Tuberculosis & $\begin{array}{l}\text { mannose-capped lipoarabinomannan } \\
\text { (ManLAM), a stimulant of antigenic biomarker } \\
\text { in serum }\end{array}$ & Indirect SERS & $\begin{array}{l}\text { Gold film-coated substrate \& gold } \\
\text { nanoparticles }\end{array}$ & $\begin{array}{l}\text { handheld Raman system }(0.18 \\
n g / m L) \& \text { benchtop } \\
\text { Ramaninstrument }(0.032 \mathrm{ng} / \mathrm{mL})\end{array}$ & [90] \\
\hline $\begin{array}{l}\text { methicillin-resistant S. aureus (MRSA) and } \\
\text { methicillin-sensitive S. aureus (MSSA) }\end{array}$ & $m e c A$ gene and cellular proteins & Direct SERS & Silver nanocolloids & $5 \%$ to $100 \%$ & [73] \\
\hline $\begin{array}{l}\text { Urinary tract infection caused by E. coli and } \\
\text { P. mirabilis }\end{array}$ & cell membrane proteins & Direct SERS & Silver nanoparticles & Not reported & [85] \\
\hline Pneumonia caused by M. pneumoniae & $\begin{array}{l}\text { Surface proteins of bacteria in clinical throat } \\
\text { swabs }\end{array}$ & Direct SERS & Silver nanorod arrays & $82 \mathrm{CFU} /$ sample & [80] \\
\hline Infections caused by Streptococcus suis II & $\begin{array}{l}\text { Muramidase released protein (MRP) antibody in } \\
\text { pig serum }\end{array}$ & Indirect SERS & Thorny gold nanoparticles & $0.1 \mathrm{pg} / \mathrm{mL}$ & [88] \\
\hline E. coli & Cellular surface antigens in real water samples & Indirect SERS & $\begin{array}{l}\text { Gold nanorods with gold-coated } \\
\text { magnetic nanoparticles }\end{array}$ & $8 \mathrm{CFU} / \mathrm{mL}$ & [84] \\
\hline Keratoconjunctivitides & Protein biomarkers in eye fluid & Direct SERS & Gold nanoparticles & $1 \mathrm{pM}$ & [91] \\
\hline Pseudomonas aeruginosa & $\begin{array}{c}\text { Pyocyanin metabolite in clinical sputum } \\
\text { samples }\end{array}$ & Indirect SERS & Silver nanorod array & $5 \mathrm{ppb}$ & [78] \\
\hline
\end{tabular}


Table 1. Cont.

\begin{tabular}{|c|c|c|c|c|c|}
\hline Disease & Target & Detection Scheme & Transducer & LOD & Ref. \\
\hline \multicolumn{6}{|c|}{ Mosquito-borne Infectious Diseases } \\
\hline West Nile Virus & Viral DNA & Indirect SERS & $\begin{array}{l}\text { Paramagnetic nanoparticles and gold } \\
\text { nanoparticles }\end{array}$ & $20-100 \mathrm{nM}$ & [92] \\
\hline Dengue & Viral DNA & Indirect SERS & Gold and silver Nanowaves & 6 attomoles & [94] \\
\hline Malaria & Parasitic DNA & Indirect SERS & nanorattles and magnetic beads & 3 picomolar & [95] \\
\hline Malaria & Ribosomal RNA in infected blood lysates & Indirect SERS & Nanorattles and magnetic beads & $200 \mathrm{fM}$ & [96] \\
\hline Zika & ZIKV Nonstructural protein 1 (NS1) protein & Indirect SERS & Silica-coated gold nanoparticles & $10 \mathrm{ng} / \mathrm{mL}$ & [97] \\
\hline West Nile Virus & WNV protein & Indirect SERS & Gold Nanostars & $2 \mathrm{ng} / \mathrm{mL}$ & [98] \\
\hline West Nile Virus and Rift Valley Virus & Antigens of WNV and RVF & Indirect SERS & $\begin{array}{l}\text { Gold nanoparticles and Paramagnetic } \\
\text { nanoparticles }\end{array}$ & $5 \mathrm{fg} / \mathrm{mL}$ & [99] \\
\hline $\begin{array}{l}\text { West Nile Virus, Valley Fever Virus and } \\
\text { Yersinia pestis }\end{array}$ & Viral pathogenic antigens & Indirect SERS & $\begin{array}{l}\text { Silica-coated gold nanoparticles and } \\
\text { Paramagnetic nanoparticles }\end{array}$ & $10 \mathrm{pg} / \mathrm{mL}$ & [100] \\
\hline Hand, Foot and Mouth Disease causing virus & Enterovirus 71 (EV71) & Direct SERS & Gold Nanostars & $10^{6}$ to $10^{8} \mathrm{pfu} / \mathrm{mL}$ & [101] \\
\hline Zika and Dengue & Nonstructural protein 1 (NS1) & Indirect SERS & Gold Nanostars & $\begin{array}{c}0.72 \mathrm{ng} / \mathrm{mL} \text { of ZIKV NS1 and } 7.67 \\
\mathrm{ng} / \mathrm{mL} \text { of DENV NS1 }\end{array}$ & [102] \\
\hline West Nile Virus and Dengue & DENV-2 and WNV proteins in serum & Direct SERS & Gold nanoparticles & $10 \mathrm{pfu} / \mathrm{mL}$ & [103] \\
\hline Malaria & $\begin{array}{l}\text { Plasmodium falciparum infected red blood cells } \\
\text { (iRBC) }\end{array}$ & Direct SERS & Silver nanorod & $1.5 \times 10^{7} / \mathrm{mL}$ & [104] \\
\hline Malaria & Hemozoin in iRBC & direct SERS & $\begin{array}{c}\text { Iron oxide core and silver shell } \\
\text { nanoparticles }\end{array}$ & $5 \mathrm{nM}$ & [113] \\
\hline Malaria & Hemozoin in iRBC & direct SERS & Silver nanoparticles & 2.5 parasites $/ \mu \mathrm{L}$ & [109] \\
\hline Malaria & Hemozoin in iRBC lysate & direct SERS & Gold-coated butterfly wings & $0.0005 \%$ and $0.005 \%$ & [114] \\
\hline
\end{tabular}


Among many different approaches, microfluidic devices, lateral-flow assays, and lab-on-a-chip assays are the most common diagnostic assay platforms that have been developed and tested for infectious diseases [94,115-120]. SERS-based assays have been integrated into these devices to be used for both qualitative and quantitative biomarker detection $[7,8,70,73,91,94,121-124]$. Integration of SERS detection schemes into lateral flow assays are commonly seen in the recent work related to infectious disease diagnosis [91,122]. Paper-based immunoassays such as LFA are desirable at the POC as they are cost-efficient and can be user friendly for a non- technically specialized end user. For instance, Choo, et al. developed a simplified LFA using hollow gold nanoparticles encoded with Raman tags and functionalized with antibodies as the SERS detection probe to specifically capture and detect staphylococcal enterotoxin B (SEB), which is a common food-poisoning pathogen (Figure 8) [122]. This approach was able to yield highly sensitive quantitative detection of SEB based on the SERS signals measured at the test zone, where the SEB-antibody conjugated SERS probe complex exist. The reported LOD for SEB using this SERS-based LFA strip was estimated to be $0.001 \mathrm{ng} \mathrm{mL}^{-1}$, which is in the range required for SEB to cause intoxication (less than $1 \mathrm{ng} \mathrm{mL}^{-1}$ ). In comparison to the enzyme-linked immunosorbent assay (ELISA)-based method, the SERS-based LFA provides approximately three orders of magnitude higher detection sensitivity. Hamad-Schifferli's group also developed LFAs using SERS nanotags for dengue and Zika detection [70,125]. The importance of their study is that they systematically examined the importance of gold nanostar morphological features and Raman reporter selection in order optimize the SERS enhancement and multiplexed detection in LFAs, respectively. They investigated the effect of the morphological features of gold nanoparticles (spherical vs. star-shaped and the varying tip curvature of gold nanostars) as SERS substrates on the sensitivity of SERS-based LFA [70]. The SERS enhancement of the Raman reporter molecules 1,2-bis(4-pyridyl)ethylene and 4-mercaptobenzoic acid were optimized and compared using different types of gold nanoparticles for multiplexed detection of zika and dengue non-structural protein 1 (NS1). They concluded that the nanoparticles with sharp tips such as nanostars provide higher enhancement factors, hence enabling higher sensitivities in SERS immunoassays. In addition, they also observed that the SERS intensity distribution within the test zone is greater in the area where the fluid first encounters the immobilized antibody, and such factors can be used to strategically design LFA to decrease the overall assay cost. In 2018, the same group focused on selecting Raman reporters for quantitative multiplexed SERS detection of protein (IgG) biomarkers in a dipstick immunoassay [125]. In this study, gold nanostars conjugated to polyclonal anti-human IgG antibodies were tagged with 15 different Raman reporters. They used machine learning to evaluate the spectral overlap and quantitative contribution of Raman reporters. Using the information gathered from the comprehensive correlation matrix analysis, they were able to select multiple reporters that provide sufficient spectral resolution and higher quantitative accuracy in multiplexed SERS-based igG biomarker detection in LFAs. 

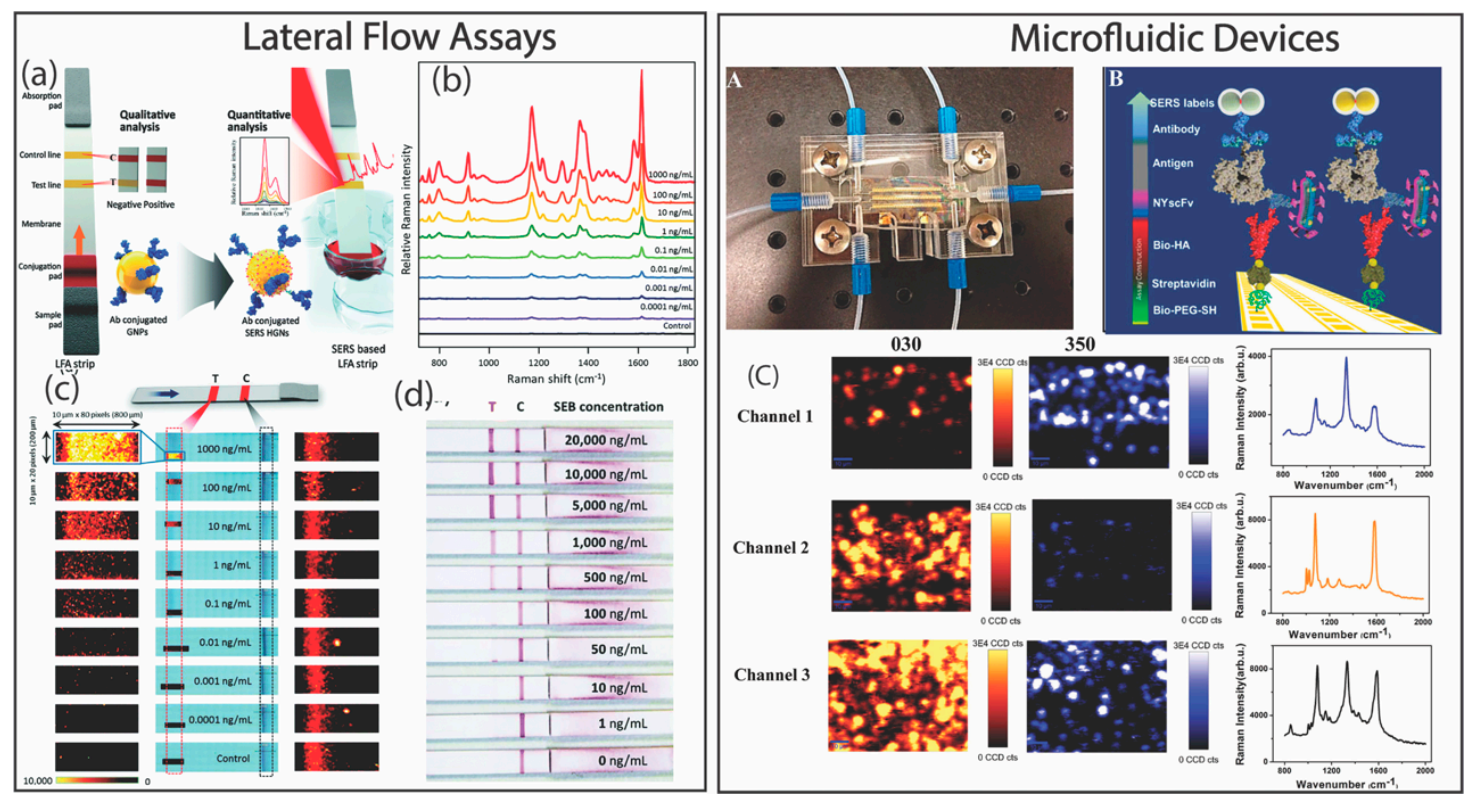

Figure 8. SERS-based diagnostic devices and assay platforms. Lateral flow assay (LFA) designs: (a) Representation of a traditional LFA and a SERS-based LFA that utilized Raman reporter-labeled hollow gold nanospheres to detect the presence of staphylococcal enterotoxin B (SEB). (b) Average SERS spectra at the mapping area of the test zone for varying concentrations of SEB. (c) SERS maps acquired using a peak intensity at $1650 \mathrm{~cm}^{-1}$ for varying concentrations of SEB concentrations. (d) Photograph of the LFA strip at varying concentrations of SEB concentrations. Reproduced with permission from Reference [122] Royal Society of Chemistry (2016). Microfluidic devices. (a) Microfluidic device used for the detection of Entamoeba histolytica using antigen as the biomarker. (b) Schematic representation of an indirect detection scheme designed to detect Entamoeba histolytica antigen biomarkers. It uses gold nanoparticle clusters functionalized with aromatic thiols as Raman reporters. (c) The duplex detection of pathogen in the three-channel microfluidic device using false-color SERS images and the corresponding average SERS spectra. Reproduced with permission from Reference [7] American Chemical Society (2014).

Microfluidic SERS immunoassays using antigen-antibody interactions are also a popular device architecture for POC infectious disease detection in clinical samples $[7,73,124]$. Trau et al. developed a conceptually new SERS diagnostic assay integrated into a microfluidic devices for duplex detection of two antigen biomarkers of the Entamoeba histolytica pathogen [7]. The bioassay platform was designed using a glass chip-coated with Raman tags-encoded gold nanoparticles (SERS substrate) which was then then fixed into a microfluidic device (Figure 8). The glass chip (SERS substrate) is comprised of multiple channels that carry different Raman tags-encoded gold nanoparticles for multiplexed detection of antigens. In order to reduce the cost associated with the device fabrication, this platform used inexpensive nanoyeast single-chain variable fragments $(\mathrm{NYscFv}$ ) reagents instead of antibodies as the recognition moieties of antigen biomarkers. Using this new SERS-based microfluid bioassays, they achieved highly specific and highly sensitive detection of individual E. histolytica antigen EHI_115350 and EHI_182030 at the LOD of $1 \mathrm{pg} / \mathrm{mL}$ and $10 \mathrm{pg} / \mathrm{mL}$, respectively. Overall this microfluid device exhibits greater potential as a SERS-based analytical platform for high throughput multiplexed detection of pathogen antigens. Konkel et al. introduced a microfluidic system coupled to a "lab-on-a-chip" system that enables label-free SERS-based rapid detection and differentiation of Staphylococcus aureus (MRSA) and methicillin-sensitive S. aureus (MSSA) in clinical isolates [73]. This integrated device is based on the working principle of an optofluidic system where the SERS detection is carried under controlled flow conditions as opposed to traditional stationary conditions. A microfluidic SERS-based assay with an optofluidic design provides many advantages such as highly reliable handling of small sample volumes and high sample throughput. By coupling the novel 
optofluidic-based "lab-on-a-chip" detection system to a confocal micro-Raman spectroscopic system, they were able to use the intrinsic SERS signature of MRSA and MSSA to investigate their epidemiology in clinical samples isolated from infected humans.

\section{Conclusions and Outlook}

The work highlighted in this review demonstrates the greater potential and the POC applicability of SERS spectroscopy as a bioanalytical technique for both qualitative and quantitative infectious disease diagnostics using biomarkers ranging from nucleic acids to proteins to metabolites. Intrinsic SERS enables the monitoring of the molecular structural changes of biomarkers during disease progression, and Raman labels- and molecular recognition elements-assisted indirect SERS detection of biomarkers offer versatile POC diagnostic potentials. Enabled by the excellent optical properties of plasmonic nanomaterials, the high sensitivity, selectivity, and multiplexing capability of SERS-based bioassays, collectively, offer characteristics of a powerful diagnostic tool that can be integrated into field-transferable devices for early and rapid infectious disease detection.

While many of the SERS-based techniques demonstrate excellent and versatile biomarker detection capabilities, it is crucial to reconsider the sensory characteristics and practical needs for their clinical and/or POC applications. In order for SERS-based sensing platforms to reach the front line of the POC detection, technique standardization and validation is highly important. The performance of the SERS-based diagnostic assays mainly depends on the quality of plasmonic nanomaterials and the nano-bio functional interface. Therefore, we have to address two main aspects of the nanoparticles-based SERS diagnostic systems to further advance them for POC diagnosis; (i) both the SERS signal stability and the SERS enhancement factor depend on the quality of the plasmonic NPs. Therefore, it is vital to ensure the batch-to-batch consistency and reproducibility of plasmonic nanoparticles-based SERS substrates for reliable and quantitative SERS-based biomarker detection. (ii) In addition, the careful fabrication of the functional nano-bio interface is critical to obtain high diagnostic specificity and accuracy. Thus, synthetic approaches for stable and reproducible surface functionalization of SERS substrates with molecular recognition elements and surface passivation ligands are needed. It will help eliminating non-specific biological interactions hence reducing SERS spectral interference and ensuring colloidal stability for stable SERS signal acquisition. An appreciable amount of effort is currently being invested by the research community to investigate these fundamental aspects of the nanoparticle-based SERS diagnostic assays $[7,17,70,73,125,126]$. Combining the current exponential improvement in both fundamental chemistry and device engineering, the widespread use of SERS-based diagnostics for infectious diseases at the POC and clinical setting is only a very few years away from us.

Author Contributions: Writing—original draft preparation, L.H. and A.G.; Conceptualization, writing—review and editing, A.S.D.S.I.

Funding: This work was funded by University of North Carolina at Charlotte.

Conflicts of Interest: The authors declare no conflict of interest.

\section{References}

1. Qasim, M.; Lim, D.-J.; Park, H.; Na, D. Nanotechnology for Diagnosis and Treatment of Infectious Diseases. J. Nanosci. Nanotechnol. 2014, 14, 7374-7387. [CrossRef]

2. Peeling, R.W.; Holmes, K.K.; Mabey, D.; Ronald, A. Rapid tests for sexually transmitted infections (STIs): the way forward. Sex. Transm. Infect. 2006, 82, v1-v6. [CrossRef] [PubMed]

3. Mabey, D.; Peeling, R.W.; Ustianowski, A.; Perkins, M.D. Diagnostics for the developing world. Nat. Rev. Microbiol. 2004, 2, 231-240. [CrossRef]

4. Manohar, C.; Andrea, T.; Anisha, G.; Gobind, D.; Zaccaria, R.P.; Roman, K.; Eliana, R.; Marco, L.; Carlo, L.; De, A.F.; et al. 3D Nanostar Dimers with a Sub-10-nm Gap for Single-/Few-Molecule Surface-Enhanced Raman Scattering. Adv. Mater. 2014, 26, 2353-2358. 
5. Gracie, K.; Correa, E.; Mabbott, S.; Dougan, J.A.; Graham, D.; Goodacre, R.; Faulds, K. Simultaneous detection and quantification of three bacterial meningitis pathogens by SERS. Chem. Sci. 2014, 5, 1030-1040. [CrossRef]

6. Domke, K.F. Surface Enhanced Raman Spectroscopy. Analytical, Biophysical and Life Science Applications. Edited by Sebastian Schlücker. Angew. Chem. Int. Ed. 2011, 50, 8226. [CrossRef]

7. Wang, Y.; Rauf, S.; Grewal, Y.S.; Spadafora, L.J.; Shiddiky, M.J.; Cangelosi, G.A.; Schlucker, S.; Trau, M. Duplex microfluidic SERS detection of pathogen antigens with nanoyeast single-chain variable fragments. Anal. Chem. 2014, 86, 9930-9938. [CrossRef] [PubMed]

8. Tran, V.; Walkenfort, B.; Konig, M.; Salehi, M.; Schlucker, S. Rapid, Quantitative, and Ultrasensitive Point-of-Care Testing: A Portable SERS Reader for Lateral Flow Assays in Clinical Chemistry. Angew. Chem. Int. Ed. Engl. 2019, 58, 442-446. [CrossRef]

9. Graham, D.; Mallinder, B.J.; Smith, W.E. Detection and identification of labeled DNA by surface enhanced resonance Raman scattering. Biopolymers 2000, 57, 85-91. [CrossRef]

10. Harper, M.M.; Dougan, J.A.; Shand, N.C.; Graham, D.; Faulds, K. Detection of SERS active labelled DNA based on surface affinity to silver nanoparticles. Analyst 2012, 137, 2063-2068. [CrossRef]

11. McQueenie, R.; Stevenson, R.; Benson, R.; MacRitchie, N.; McInnes, I.; Maffia, P.; Faulds, K.; Graham, D.; Brewer, J.; Garside, P. Detection of inflammation in vivo by surface-enhanced Raman scattering provides higher sensitivity than conventional fluorescence imaging. Anal. Chem. 2012, 84, 5968-5975. [CrossRef]

12. Alvarez-Puebla, R.A.; Liz-Marzan, L.M. SERS-Based Diagnosis and Biodetection. Small 2010, 6, 604-610. [CrossRef]

13. Bodelon, G.; Montes-Garcia, V.; Lopez-Puente, V.; Hill, E.H.; Hamon, C.; Sanz-Ortiz, M.; Rodal-Cedeira, S.; Costas, C.; Celiksoy, S.; Perez-Juste, I.; et al. Detection and imaging of quorum sensing in Pseudomonas aeruginosa biofilm communities by surface-enhanced resonance Raman scattering. Nat. Mater. 2016, 15, 1203-1211. [CrossRef]

14. Moskovits, M. Surface-enhanced Raman spectroscopy: A brief retrospective. J. Raman Spectrosc. 2005, 36, 485-496. [CrossRef]

15. Hao, E.; Schatz, G.; Hupp, J. Synthesis and Optical Properties of Anisotropic Metal Nanoparticles. J. Fluoresc. 2004, 14, 331-341. [CrossRef]

16. Kelly, K.L.; Coronado, E.; Zhao, L.L.; Schatz, G.C. The optical properties of metal nanoparticles: The influence of size, shape, and dielectric environment. J. Phys. Chem. B 2003, 107, 668. [CrossRef]

17. De Silva Indrasekara, A.S.; Johnson, S.F.; Odion, R.A.; Vo-Dinh, T. Manipulation of the Geometry and Modulation of the Optical Response of Surfactant-Free Gold Nanostars: A Systematic Bottom-Up Synthesis. ACS Omega 2018, 3, 2202-2210. [CrossRef]

18. Indrasekara, A.S.D.; Thomas, R.; Fabris, L. Plasmonic properties of regiospecific core-satellite assemblies of gold nanostars and nanospheres. Phys. Chem. Chem. Phys. 2015, 17, 21133-21142. [CrossRef]

19. Fabris, L.; Indrasekara, A.S. Gold Nanostar Substrates for SERS Sensing in the Femtomolar Regime. US Patent No US10024800B2, 2015.

20. Perets, E.A.; Indrasekara, A.S.D.S.; Kurmis, A.; Atlasevich, N.; Fabris, L.; Arslanoglu, J. Carboxy-terminated immuno-SERS tags overcome non-specific aggregation for the robust detection and localization of organic media in artworks. Analyst 2015, 140, 5971-5980. [CrossRef]

21. Indrasekara, A.S.D.S.; Paladini, B.J.; Naczynski, D.J.; Starovoytov, V.; Moghe, P.V.; Fabris, L. Dimeric Gold Nanoparticle Assemblies as Tags for SERS-Based Cancer Detection. Adv. Healthc. Mater. 2013, 2, 1370-1376. [CrossRef]

22. Personick, M.L.; Langille, M.R.; Zhang, J.; Mirkin, C.A. Shape Control of Gold Nanoparticles by Silver Underpotential Deposition. Nano Lett. 2011, 11, 3394-3398. [CrossRef]

23. Xue, C.; Millstone, J.E.; Li, S.; Mirkin, C.A. Plasmon-Driven Synthesis of Triangular Core?Shell Nanoprisms from Gold Seeds. Angew. Chem. Int. Ed. 2007, 46, 8436-8439. [CrossRef]

24. Rosi, N.L.; Mirkin, C.A. Nanostructures in biodiagnostics. Chem. Rev. 2005, 105, 1547-1562. [CrossRef]

25. Murphy, C.J.; Sau, T.K.; Gole, A.M.; Orendorff, C.J.; Gao, J.; Gou, L.; Hunyadi, S.E.; Li, T. Anisotropic Metal Nanoparticles: Synthesis, Assembly, and Optical Applications. J. Phys. Chem. B 2005, 109, 13857-13870. [CrossRef]

26. Kleinman, S.L.; Sharma, B.; Blaber, M.G.; Henry, A.-I.; Valley, N.; Freeman, R.G.; Natan, M.J.; Schatz, G.C.; Van Duyne, R.P. Structure Enhancement Factor Relationships in Single Gold Nanoantennas by Surface-Enhanced Raman Excitation Spectroscopy. J. Am. Chem. Soc. 2013, 135, 301-308. [CrossRef] 
27. Sharma, B.; Fernanda Cardinal, M.; Kleinman, S.L.; Greeneltch, N.G.; Frontiera, R.R.; Blaber, M.G.; Schatz, G.C.; Van Duyne, R.P. High-performance SERS substrates: Advances and challenges. MRS Bull. 2013, 38, 615-624. [CrossRef]

28. Greeneltch, N.G.; Blaber, M.G.; Henry, A.-I.; Schatz, G.C.; Van Duyne, R.P. Immobilized Nanorod Assemblies: Fabrication and Understanding of Large Area Surface-Enhanced Raman Spectroscopy Substrates. Anal. Chem. 2013, 85, 2297-2303. [CrossRef]

29. Stiles, P.L.; Dieringer, J.A.; Shah, N.C.; Van Duyne, R.P. Surface-Enhanced Raman Spectroscopy. Annu. Rev. Anal. Chem. 2008, 1, 601-626. [CrossRef]

30. Kneipp, K.; Dasari, R.R.; Wang, Y. Near-Infrared Surface-Enhanced Raman-Scattering (Nir Sers) on Colloidal Silver and Gold. Appl. Spectrosc. 1994, 48, 951-955. [CrossRef]

31. Michota, A.; Bukowska, J. Surface-enhanced Raman scattering (SERS) of 4-mercaptobenzoic acid on silver and gold substrates. J. Raman Spectrosc. 2003, 34, 21-25. [CrossRef]

32. Alvarez-Puebla, R.; Dos, S., Jr.; Aroca, R.F. Surface-enhanced Raman scattering for ultrasensitive chemical analysis of 1 and 2-naphthalenethiols. Analyst 2004, 129, 1251-1256. [CrossRef]

33. Fabris, L.; Dante, M.; Nguyen, T.-Q.; Tok, J.B.H.; Bazan, G.C. SERS Aptatags: New Responsive Metallic Nanostructures for Heterogeneous Protein Detection by Surface Enhanced Raman Spectroscopy. Adv. Funct. Mater. 2008, 18, 2518-2525. [CrossRef]

34. Indrasekara, A.S.D.S.; Meyers, S.; Shubeita, S.; Feldman, L.C.; Gustafsson, T.; Fabris, L. Gold nanostar substrates for SERS-based chemical sensing in the femtomolar regime. Nanoscale 2014, 6, 8891-8899. [CrossRef]

35. Millstone, J.E.; Park, S.; Shuford, K.L.; Qin, L.; Schatz, G.C.; Mirkin, C.A. Observation of a Quadrupole Plasmon Mode for a Colloidal Solution of Gold Nanoprisms. J. Am. Chem. Soc. 2005, 127, 5312-5313. [CrossRef]

36. Fales, A.M.; Yuan, H.; Vo-Dinh, T. Silica-Coated Gold Nanostars for Combined Surface-Enhanced Raman Scattering (SERS) Detection and Singlet-Oxygen Generation: A Potential Nanoplatform for Theranostics. Langmuir 2011, 27, 12186-12190. [CrossRef]

37. Hsiangkuo, Y.; Christopher, G.K.; Hanjun, H.; Christy, M.W.; Gerald A Grant and, T.V. Gold nanostars: surfactant-free synthesis, 3D modelling, and two-photon photoluminescence imaging. Nanotechnology 2012, 23, 075102.

38. Hao, F.; Nehl, C.L.; Hafner, J.H.; Nordlander, P. Plasmon Resonances of a Gold Nanostar. Nano Lett. 2007, 7, 729-732. [CrossRef] [PubMed]

39. Alvarez-Puebla, R.; Liz-Marzaİn, L.M.; de Abajo, F.J.G. Light Concentration at the Nanometer Scale. J. Phys. Chem. Lett. 2010, 1, 2428-2434. [CrossRef]

40. Braun, G.B.; Lee, S.J.; Laurence, T.; Fera, N.; Fabris, L.; Bazan, G.C.; Moskovits, M.; Reich, N.O. Generalized Approach to SERS-Active Nanomaterials via Controlled Nanoparticle Linking, Polymer Encapsulation, and Small-Molecule Infusion. J. Phys. Chem. C 2009, 113, 13622-13629. [CrossRef]

41. Talley, C.E.; Jackson, J.B.; Oubre, C.; Grady, N.K.; Hollars, C.W.; Lane, S.M.; Huser, T.R.; Nordlander, P.; Halas, N.J. Surface-Enhanced Raman Scattering from Individual Au Nanoparticles and Nanoparticle Dimer Substrates. Nano Lett. 2005, 5, 1569-1574. [CrossRef]

42. Schutz, M.; Schlucker, S. Molecularly linked 3D plasmonic nanoparticle core/satellite assemblies: SERS nanotags with single-particle Raman sensitivity. Phys. Chem. Chem. Phys. 2015, 17, 24356. [CrossRef]

43. Romo-Herrera, J.; Alvarez-Puebla, R.; Liz-Marzan, L. Controlled assembly of plasmonic colloidal nanoparticle clusters. Nanoscale 2011, 3, 1304-1315. [CrossRef]

44. Chen, G.; Wang, Y.; Yang, M.; Xu, J.; Goh, S.J.; Pan, M.; Chen, H. Measuring Ensemble-Averaged Surface-Enhanced Raman Scattering in the Hotspots of Colloidal Nanoparticle Dimers and Trimers. J. Am. Chem. Soc. 2010, 132, 3644-3645. [CrossRef]

45. Malinsky, M.D.; Kelly, K.L.; Schatz, G.C.; Van Duyne, R.P. Chain Length Dependence and Sensing Capabilities of the Localized Surface Plasmon Resonance of Silver Nanoparticles Chemically Modified with Alkanethiol Self-Assembled Monolayers. J. Am. Chem. Soc. 2001, 123, 1471-1482. [CrossRef]

46. Wustholz, K.L.; Henry, A.-I.; McMahon, J.M.; Freeman, R.G.; Valley, N.; Piotti, M.E.; Natan, M.J.; Schatz, G.C.; Duyne, R.P.V. Structure-Activity Relationships in Gold Nanoparticle Dimers and Trimers for Surface-Enhanced Raman Spectroscopy. J. Am. Chem. Soc. 2010, 132, 10903-10910. [CrossRef] 
47. Rahme, K.; Chen, L.; Hobbs, R.G.; Morris, M.A.; O'Driscoll, C.; Holmes, J.D. PEGylated gold nanoparticles: Polymer quantification as a function of PEG lengths and nanoparticle dimensions. RSC Adv. 2013, 3, 6085-6094. [CrossRef]

48. Chen, S.; Yang, M.; Hong, S.; Lu, C. Nonionic fluorosurfactant as an ideal candidate for one-step modification of gold nanorods. Nanoscale 2014. [CrossRef]

49. Austin, L.A.; Mackey, M.A.; Dreaden, E.C.; El-Sayed, M.A. The optical, photothermal, and facile surface chemical properties of gold and silver nanoparticles in biodiagnostics, therapy, and drug delivery. Arch. Toxicol. 2014, 88, 1391-1417. [CrossRef]

50. Park, S.Y.; Lee, J.-S.; Georganopoulou, D.; Mirkin, C.A.; Schatz, G.C. Structures of DNA-Linked Nanoparticle Aggregates. J. Phys. Chem. B 2006, 110, 12673-12681. [CrossRef]

51. Brennan, J.L.; Hatzakis, N.S.; Tshikhudo, T.R.; Razumas, V.; Patkar, S.; Vind, J.; Svendsen, A.; Nolte, R.J.M.; Rowan, A.E.; Brust, M. Bionanoconjugation via Click Chemistry: The Creation of Functional Hybrids of Lipases and Gold Nanoparticles. Bioconj. Chem. 2006, 17, 1373-1375. [CrossRef]

52. Krpetić, Ž.; Nativo, P.; Porta, F.; Brust, M. A Multidentate Peptide for Stabilization and Facile Bioconjugation of Gold Nanoparticles. Bioconj. Chem. 2009, 20, 619-624. [CrossRef]

53. Kanaras, A.G.; Kamounah, F.S.; Schaumburg, K.; Kiely, C.J.; Brust, M. Thioalkylated tetraethylene glycol: A new ligand for water soluble monolayer protected gold clusters. Chem. Commun. 2002, 2294-2295. [CrossRef]

54. Barhoumi, A.; Halas, N.J. Label-Free Detection of DNA Hybridization Using Surface Enhanced Raman Spectroscopy. J. Am. Chem. Soc. 2010, 132, 12792-12793. [CrossRef]

55. Dondapati, S.K.; Sau, T.K.; Hrelescu, C.; Klar, T.A.; Stefani, F.D.; Feldmann, J. Label-free Biosensing Based on Single Gold Nanostars as Plasmonic Transducers. ACS Nano 2010, 4, 6318-6322. [CrossRef]

56. Papadopoulou, E.; Bell, S.E.J. Label-Free Detection of Single-Base Mismatches in DNA by Surface-Enhanced Raman Spectroscopy. Angew. Chem. Int. Ed. 2011, 50, 9058-9061. [CrossRef]

57. Ngo, H.T.; Wang, H.-N.; Fales, A.M.; Vo-Dinh, T. Label-Free DNA Biosensor Based on SERS Molecular Sentinel on Nanowave Chip. Anal. Chem. 2013, 85, 6378-6383. [CrossRef]

58. Xu, L.-J.; Lei, Z.-C.; Li, J.; Zong, C.; Yang, C.J.; Ren, B. Label-Free Surface-Enhanced Raman Spectroscopy Detection of DNA with Single-Base Sensitivity. J. Am. Chem. Soc. 2015, 137, 5149-5154. [CrossRef]

59. Dina, N.E.; Zhou, H.; Colnita, A.; Leopold, N.; Szoke-Nagy, T.; Coman, C.; Haisch, C. Rapid single-cell detection and identification of pathogens by using surface-enhanced Raman spectroscopy. Analyst 2017, 142, 1782-1789. [CrossRef]

60. Graham, D.; Mallinder, B.J.; Whitcombe, D.; Watson, N.D.; Smith, W.E. Simple Multiplex Genotyping by Surface-Enhanced Resonance Raman Scattering. Anal. Chem. 2002, 74, 1069-1074. [CrossRef]

61. Yu, C.; Irudayaraj, J. Quantitative Evaluation of Sensitivity and Selectivity of Multiplex NanoSPR Biosensor Assays. Biophys. J. 2007, 93, 3684-3692. [CrossRef]

62. Sun, L.; Yu, C.; Irudayaraj, J. Raman multiplexers for alternative gene splicing. Anal. Chem. 2008, 80, 3342-3349. [CrossRef]

63. von Maltzahn, G.; Centrone, A.; Park, J.-H.; Ramanathan, R.; Sailor, M.J.; Hatton, T.A.; Bhatia, S.N. SERS-Coded Gold Nanorods as a Multifunctional Platform for Densely Multiplexed Near-Infrared Imaging and Photothermal Heating. Adv. Mater. 2009, 21, 3175-3180. [CrossRef]

64. Zavaleta, C.L.; Smith, B.R.; Walton, I.; Doering, W.; Davis, G.; Shojaei, B.; Natan, M.J.; Gambhir, S.S. Multiplexed imaging of surface enhanced Raman scattering nanotags in living mice using noninvasive Raman spectroscopy. Proc. Natl. Acad. Sci. USA 2009, 106, 13511-13516. [CrossRef]

65. Fabris, L.; Schierhorn, M.; Moskovits, M.; Bazan, G.C. Aptatag-Based Multiplexed Assay for Protein Detection by Surface-Enhanced Raman Spectroscopy. Small 2010, 6, 1550-1557. [CrossRef]

66. Kang, T.; Yoo, S.M.; Yoon, I.; Lee, S.Y.; Kim, B. Patterned Multiplex Pathogen DNA Detection by Au Particle-on-Wire SERS Sensor. Nano Lett. 2010, 10, 1189-1193. [CrossRef]

67. Pallaoro, A.; Braun, G.B.; Moskovits, M. Quantitative ratiometric discrimination between noncancerous and cancerous prostate cells based on neuropilin-1 overexpression. Proc. Natl. Acad. Sci. USA 2011. [CrossRef]

68. Kim, J.-Y.; Lee, J.-S. Multiplexed DNA Detection with DNA-Functionalized Silver and Silver/Gold Nanoparticle Superstructure Probes. Bull. Korean Chem. Soc. 2012, 33, 221-226. [CrossRef]

69. Wang, H.-N.; Crawford, B.M.; Fales, A.M.; Bowie, M.L.; Seewaldt, V.L.; Vo-Dinh, T. Multiplexed Detection of MicroRNA Biomarkers Using SERS-Based Inverse Molecular Sentinel (iMS) Nanoprobes. J. Phys. Chem. C 2016, 120, 21047-21055. [CrossRef] 
70. Sánchez-Purrà, M.; Roig-Solvas, B.; Versiani, A.; Rodriguez-Quijada, C.; de Puig, H.; Bosch, I.; Gehrke, L.; Hamad-Schifferli, K. Design of SERS nanotags for multiplexed lateral flow immunoassays. Mol. Syst. Des. Eng. 2017, 2, 401-409. [CrossRef]

71. Wang, H.-N.; Fales, A.M.; Zaas, A.K.; Woods, C.W.; Burke, T.; Ginsburg, G.S.; Vo-Dinh, T. Surface-enhanced Raman scattering molecular sentinel nanoprobes for viral infection diagnostics. Anal. Chim. Acta 2013, 786, 153-158. [CrossRef]

72. Strelau, K.K.; Brinker, A.; Schnee, C.; Weber, K.; Moeller, R.; Popp, J. Detection of PCR products amplified from DNA of epizootic pathogens using magnetic nanoparticles and SERS. J. Raman Spectrosc. 2011, 42, 243-250. [CrossRef]

73. Lu, X.; Samuelson, D.R.; Xu, Y.; Zhang, H.; Wang, S.; Rasco, B.A.; Xu, J.; Konkel, M.E. Detecting and tracking nosocomial methicillin-resistant Staphylococcus aureus using a microfluidic SERS biosensor. Anal. Chem. 2013, 85, 2320-2327. [CrossRef]

74. Kamińska, A.; Witkowska, E.; Kowalska, A.; Skoczyńska, A.; Ronkiewicz, P.; Szymborski, T.; Waluk, J. Rapid detection and identification of bacterial meningitis pathogens in ex vivo clinical samples by SERS method and principal component analysis. Anal. Methods 2016, 8, 4521-4529. [CrossRef]

75. De, S.I.; Fabris, L. SERS-based approaches toward genetic profiling. Bioanalysis 2015, 7, 263-278.

76. Negri, P.; Dluhy, R.A. Detection of genetic markers related to high pathogenicity in influenza by SERS. Analyst 2013, 138, 4877-4884. [CrossRef]

77. Lee, C.; Carney, R.P.; Hazari, S.; Smith, Z.J.; Knudson, A.; Robertson, C.S.; Lam, K.S.; Wachsmann-Hogiu, S. 3D plasmonic nanobowl platform for the study of exosomes in solution. Nanoscale 2015, 7, 9290-9297. [CrossRef]

78. Wu, X.; Chen, J.; Li, X.; Zhao, Y.; Zughaier, S.M. Culture-free diagnostics of Pseudomonas aeruginosa infection by silver nanorod array based SERS from clinical sputum samples. Nanomedicine 2014, 10, 1863-1870. [CrossRef]

79. Hennigan, S.L.; Driskell, J.D.; Ferguson-Noel, N.; Dluhy, R.A.; Zhao, Y.; Tripp, R.A.; Krause, D.C. Detection and differentiation of avian mycoplasmas by surface-enhanced Raman spectroscopy based on a silver nanorod array. Appl. Environ. Microbiol. 2012, 78, 1930-1935. [CrossRef]

80. Hennigan, S.L.; Driskell, J.D.; Dluhy, R.A.; Zhao, Y.; Tripp, R.A.; Waites, K.B.; Krause, D.C. Detection of Mycoplasma pneumoniae in simulated and true clinical throat swab specimens by nanorod array-surface-enhanced Raman spectroscopy. PLoS ONE 2010, 5, e13633. [CrossRef]

81. Fan, Z.; Senapati, D.; Khan, S.A.; Singh, A.K.; Hamme, A.; Yust, B.; Sardar, D.; Ray, P.C. Popcorn-shaped magnetic core-plasmonic shell multifunctional nanoparticles for the targeted magnetic separation and enrichment, label-free SERS imaging, and photothermal destruction of multidrug-resistant bacteria. Chemistry 2013, 19, 2839-2847. [CrossRef]

82. Muhamadali, H.; Subaihi, A.; Mohammadtaheri, M.; Xu, Y.; Ellis, D.I.; Ramanathan, R.; Bansal, V.; Goodacre, R. Rapid, accurate, and comparative differentiation of clinically and industrially relevant microorganisms via multiple vibrational spectroscopic fingerprinting. Analyst 2016, 141, 5127-5136. [CrossRef]

83. Prucek, R.; Ranc, V.; Kvitek, L.; Panacek, A.; Zboril, R.; Kolar, M. Reproducible discrimination between gram-positive and gram-negative bacteria using surface enhanced Raman spectroscopy with infrared excitation. Analyst 2012, 137, 2866-2870. [CrossRef]

84. Guven, B.; Basaran-Akgul, N.; Temur, E.; Tamer, U.; Boyaci, I.H. SERS-based sandwich immunoassay using antibody coated magnetic nanoparticles for Escherichia coli enumeration. Analyst 2011, 136, 740-748. [CrossRef]

85. Mircescu, N.E.; Zhou, H.; Leopold, N.; Chis, V.; Ivleva, N.P.; Niessner, R.; Wieser, A.; Haisch, C. Towards a receptor-free immobilization and SERS detection of urinary tract infections causative pathogens. Anal. Bioanal. Chem. 2014, 406, 3051-3058. [CrossRef]

86. Fan, Z.; Kanchanapally, R.; Ray, P.C. Hybrid Graphene Oxide Based Ultrasensitive SERS Probe for Label-Free Biosensing. J. Phys. Chem. Lett. 2013, 4, 3813-3818. [CrossRef]

87. Premasiri, W.R.; Chen, Y.; Williamson, P.M.; Bandarage, D.C.; Pyles, C.; Ziegler, L.D. Rapid urinary tract infection diagnostics by surface-enhanced Raman spectroscopy (SERS): identification and antibiotic susceptibilities. Anal. Bioanal. Chem. 2017, 409, 3043-3054. [CrossRef] 
88. Chen, K.; Han, H.; Luo, Z. Streptococcus suis II immunoassay based on thorny gold nanoparticles and surface enhanced Raman scattering. Analyst 2012, 137, 1259-1264. [CrossRef]

89. MacLaughlin, C.M.; Mullaithilaga, N.; Yang, G.; Ip, S.Y.; Wang, C.; Walker, G.C. Surface-enhanced Raman scattering dye-labeled Au nanoparticles for triplexed detection of leukemia and lymphoma cells and SERS flow cytometry. Langmuir 2013, 29, 1908-1919. [CrossRef]

90. Owens, N.A.; Laurentius, L.B.; Porter, M.D.; Li, Q.; Wang, S.; Chatterjee, D. Handheld Raman Spectrometer Instrumentation for Quantitative Tuberculosis Biomarker Detection: A Performance Assessment for Point-of-Need Infectious Disease Diagnostics. Appl. Spectrosc. 2018, 72, 1104-1115. [CrossRef]

91. Kim, W.; Lee, J.C.; Shin, J.H.; Jin, K.H.; Park, H.K.; Choi, S. Instrument-Free Synthesizable Fabrication of Label-Free Optical Biosensing Paper Strips for the Early Detection of Infectious Keratoconjunctivitides. Anal. Chem. 2016, 88, 5531-5537. [CrossRef]

92. Zhang, H.; Harpster, M.H.; Park, H.J.; Johnson, P.A. Surface-Enhanced Raman Scattering Detection of DNA Derived from the West Nile Virus Genome Using Magnetic Capture of Raman-Active Gold Nanoparticles. Anal. Chem. 2011, 83, 254-260. [CrossRef]

93. Zhang, H.; Harpster, M.H.; Wilson, W.C.; Johnson, P.A. Surface-Enhanced Raman Scattering Detection of DNAs Derived from Virus Genomes Using Au-Coated Paramagnetic Nanoparticles. Langmuir 2012, 28, 4030-4037. [CrossRef]

94. Ngo, H.T.; Wang, H.N.; Fales, A.M.; Nicholson, B.P.; Woods, C.W.; Vo-Dinh, T. DNA bioassay-on-chip using SERS detection for dengue diagnosis. Analyst 2014, 139, 5655-5659. [CrossRef]

95. Ngo, H.T.; Gandra, N.; Fales, A.M.; Taylor, S.M.; Vo-Dinh, T. Sensitive DNA detection and SNP discrimination using ultrabright SERS nanorattles and magnetic beads for malaria diagnostics. Biosens. Bioelectron. 2016, 81, 8-14. [CrossRef]

96. Ngo, H.T.; Freedman, E.; Odion, R.A.; Strobbia, P.; De Silva Indrasekara, A.S.; Vohra, P.; Taylor, S.M.; Vo-Dinh, T. Direct Detection of Unamplified Pathogen RNA in Blood Lysate using an Integrated Lab-in-a-Stick Device and Ultrabright SERS Nanorattles. Sci. Rep. 2018, 8, 4075. [CrossRef]

97. Camacho, S.A.; Sobral-Filho, R.G.; Aoki, P.H.B.; Constantino, C.J.L.; Brolo, A.G. Zika Immunoassay Based on Surface-Enhanced Raman Scattering Nanoprobes. ACS Sens. 2018, 3, 587-594. [CrossRef]

98. Neng, J.; Harpster, M.H.; Zhang, H.; Mecham, J.O.; Wilson, W.C.; Johnson, P.A. A versatile SERS-based immunoassay for immunoglobulin detection using antigen-coated gold nanoparticles and malachite green-conjugated protein A/G. Biosens. Bioelectron. 2010, 26, 1009-1015. [CrossRef]

99. Neng, J.; Harpster, M.H.; Wilson, W.C.; Johnson, P.A. Surface-enhanced Raman scattering (SERS) detection of multiple viral antigens using magnetic capture of SERS-active nanoparticles. Biosens. Bioelectron. 2013, 41, 316-321. [CrossRef]

100. Neng, J.; Li, Y.; Driscoll, A.J.; Wilson, W.C.; Johnson, P.A. Detection of Multiple Pathogens in Serum Using Silica-Encapsulated Nanotags in a Surface-Enhanced Raman Scattering-Based Immunoassay. J. Agric. Food Chem. 2018, 66, 5707-5712. [CrossRef]

101. Reyes, M.; Piotrowski, M.; Ang, S.K.; Chan, J.; He, S.; Chu, J.J.H.; Kah, J.C.Y. Exploiting the Anti-Aggregation of Gold Nanostars for Rapid Detection of Hand, Foot, and Mouth Disease Causing Enterovirus 71 Using Surface-Enhanced Raman Spectroscopy. Anal. Chem. 2017, 89, 5373-5381. [CrossRef]

102. Sanchez-Purra, M.; Carre-Camps, M.; de Puig, H.; Bosch, I.; Gehrke, L.; Hamad-Schifferli, K. Surface-Enhanced Raman Spectroscopy-Based Sandwich Immunoassays for Multiplexed Detection of Zika and Dengue Viral Biomarkers. ACS Infect. Dis. 2017, 3, 767-776. [CrossRef]

103. Paul, A.M.; Fan, Z.; Sinha, S.S.; Shi, Y.; Le, L.; Bai, F.; Ray, P.C. Bio-Conjugated Gold Nanoparticle Based SERS Probe for Ultrasensitive Identification of Mosquito-Borne Viruses Using Raman Fingerprinting. J. Phys. Chem. C Nanomater. Interfaces 2015, 119, 23669-23775. [CrossRef]

104. Chen, F.; Flaherty, B.R.; Cohen, C.E.; Peterson, D.S.; Zhao, Y. Direct detection of malaria infected red blood cells by surface enhanced Raman spectroscopy. Nanomedicine 2016, 12, 1445-1451. [CrossRef]

105. Bilal, M.; Saleem, M.; Amanat, S.T.; Shakoor, H.A.; Rashid, R.; Mahmood, A.; Ahmed, M. Optical diagnosis of malaria infection in human plasma using Raman spectroscopy. J. Biomed. Opt. 2015, 20, 017002. [CrossRef]

106. Bruckner, M.; Becker, K.; Popp, J.; Frosch, T. Fiber array based hyperspectral Raman imaging for chemical selective analysis of malaria-infected red blood cells. Anal. Chim. Acta 2015, 894, 76-84. [CrossRef]

107. Hobro, A.J.; Konishi, A.; Coban, C.; Smith, N.I. Raman spectroscopic analysis of malaria disease progression via blood and plasma samples. Analyst 2013, 138, 3927-3933. [CrossRef] 
108. Kozicki, M.; Czepiel, J.; Biesiada, G.; Nowak, P.; Garlicki, A.; Weselucha-Birczynska, A. The ring-stage of Plasmodium falciparum observed in RBCs of hospitalized malaria patients. Analyst 2015, 140, 8007-8016. [CrossRef]

109. Chen, K.; Yuen, C.; Aniweh, Y.; Preiser, P.; Liu, Q. Towards ultrasensitive malaria diagnosis using surface enhanced Raman spectroscopy. Sci. Rep. 2016, 6, 20177. [CrossRef]

110. Wood, B.R.; Langford, S.J.; Cooke, B.M.; Glenister, F.K.; Lim, J.; McNaughton, D. Raman imaging of hemozoin within the food vacuole ofPlasmodium falciparumtrophozoites. FEBS Lett. 2003, 554, 247-252. [CrossRef]

111. Wood, B.R.; Langford, S.J.; Cooke, B.M.; Lim, J.; Glenister, F.K.; Duriska, M.; Unthank, J.K.; McNaughton, D. Resonance Raman Spectroscopy Reveals New Insight into the Electronic Structure of $\beta$-Hematin and Malaria Pigment. J. Am. Chem. Soc. 2004, 126, 9233-9239. [CrossRef]

112. Frosch, T.; Koncarevic, S.; Becker, K.; Popp, J. Morphology-sensitive Raman modes of the malaria pigment hemozoin. Analyst 2009, 134, 1126-1132. [CrossRef]

113. Yuen, C.; Liu, Q. Magnetic field enriched surface enhanced resonance Raman spectroscopy for early malaria diagnosis. Biomed. Opt. 2012, 17, 017005. [CrossRef]

114. Garrett, N.L.; Sekine, R.; Dixon, M.W.; Tilley, L.; Bambery, K.R.; Wood, B.R. Bio-sensing with butterfly wings: Naturally occurring nano-structures for SERS-based malaria parasite detection. Phys. Chem. Chem. Phys. 2015, 17, 21164-21168. [CrossRef]

115. DeChiara, N.S.; Wilson, D.J.; Mace, C.R. An Open Software Platform for the Automated Design of Paper-Based Microfluidic Devices. Sci. Rep. 2017, 7, 16224. [CrossRef]

116. Fu, E.; Liang, T.; Spicar-Mihalic, P.; Houghtaling, J.; Ramachandran, S.; Yager, P. Two-dimensional paper network format that enables simple multistep assays for use in low-resource settings in the context of malaria antigen detection. Anal. Chem. 2012, 84, 4574-4579. [CrossRef]

117. Anderson, C.E.; Holstein, C.A.; Strauch, E.M.; Bennett, S.; Chevalier, A.; Nelson, J.; Fu, E.; Baker, D.; Yager, P. Rapid Diagnostic Assay for Intact Influenza Virus Using a High Affinity Hemagglutinin Binding Protein. Anal. Chem. 2017, 89, 6608-6615. [CrossRef]

118. Zagorovsky, K.; Chan, W.C. A plasmonic DNAzyme strategy for point-of-care genetic detection of infectious pathogens. Angew. Chem. Int. Ed. Engl. 2013, 52, 3168-3171. [CrossRef]

119. Grant, B.D.; Smith, C.A.; Karvonen, K.; Richards-Kortum, R. Highly Sensitive Two-Dimensional Paper Network Incorporating Biotin-Streptavidin for the Detection of Malaria. Anal. Chem. 2016, 88, 2553-2557. [CrossRef]

120. Shanmukh, S.; Jones, L.; Zhao, Y.P.; Driskell, J.D.; Tripp, R.A.; Dluhy, R.A. Identification and classification of respiratory syncytial virus (RSV) strains by surface-enhanced Raman spectroscopy and multivariate statistical techniques. Anal. Bioanal. Chem. 2008, 390, 1551-1555. [CrossRef]

121. Fu, X.; Cheng, Z.; Yu, J.; Choo, P.; Chen, L.; Choo, J. A SERS-based lateral flow assay biosensor for highly sensitive detection of HIV-1 DNA. Biosens. Bioelectron. 2016, 78, 530-537. [CrossRef]

122. Hwang, J.; Lee, S.; Choo, J. Application of a SERS-based lateral flow immunoassay strip for the rapid and sensitive detection of staphylococcal enterotoxin B. Nanoscale 2016, 8, 11418-11425. [CrossRef]

123. Park, H.J.; Yang, S.C.; Choo, J. Early Diagnosis of Influenza Virus A Using Surface-enhanced Raman Scattering-based Lateral Flow Assay. Bull. Korean Chem. Soc. 2016, 37, 2019-2024. [CrossRef]

124. Kaminska, A.; Witkowska, E.; Winkler, K.; Dziecielewski, I.; Weyher, J.L.; Waluk, J. Detection of Hepatitis B virus antigen from human blood: SERS immunoassay in a microfluidic system. Biosens. Bioelectron. 2015, 66, 461-467. [CrossRef]

125. Sanchez-Purra, M.; Roig-Solvas, B.; Rodriguez-Quijada, C.; Leonardo, B.M.; Hamad-Schifferli, K. Reporter Selection for Nanotags in Multiplexed Surface Enhanced Raman Spectroscopy Assays. ACS Omega 2018, 3, 10733-10742. [CrossRef]

126. De Silva Indrasekara, A.S.; Norton, S.J.; Geitner, N.K.; Crawford, B.M.; Wiesner, M.R.; Vo-Dinh, T. Tailoring the Core-Satellite Nanoassembly Architectures by Tuning Internanoparticle Electrostatic Interactions. Langmuir 2018, 34, 14617-14623. [CrossRef]

(C) 2019 by the authors. Licensee MDPI, Basel, Switzerland. This article is an open access article distributed under the terms and conditions of the Creative Commons Attribution (CC BY) license (http:/ / creativecommons.org/licenses/by/4.0/). 